This item was submitted to Loughborough's Research Repository by the author.

Items in Figshare are protected by copyright, with all rights reserved, unless otherwise indicated.

\title{
Knowledge transfer in IT offshoring relationships: the roles of social capital, efficacy and outcome expectations
}

PLEASE CITE THE PUBLISHED VERSION

http://dx.doi.org/10.1111/isj.12027

PUBLISHER

(C) Wiley Publishing Ltd

VERSION

AM (Accepted Manuscript)

LICENCE

CC BY-NC-ND 4.0

\section{REPOSITORY RECORD}

Zimmermann, Angelika, and M.N. Ravishankar. 2019. "Knowledge Transfer in IT Offshoring Relationships: The Roles of Social Capital, Efficacy and Outcome Expectations". figshare. https://hdl.handle.net/2134/12847. 
This item was submitted to Loughborough's Institutional Repository (https://dspace.lboro.ac.uk/) by the author and is made available under the following Creative Commons Licence conditions.

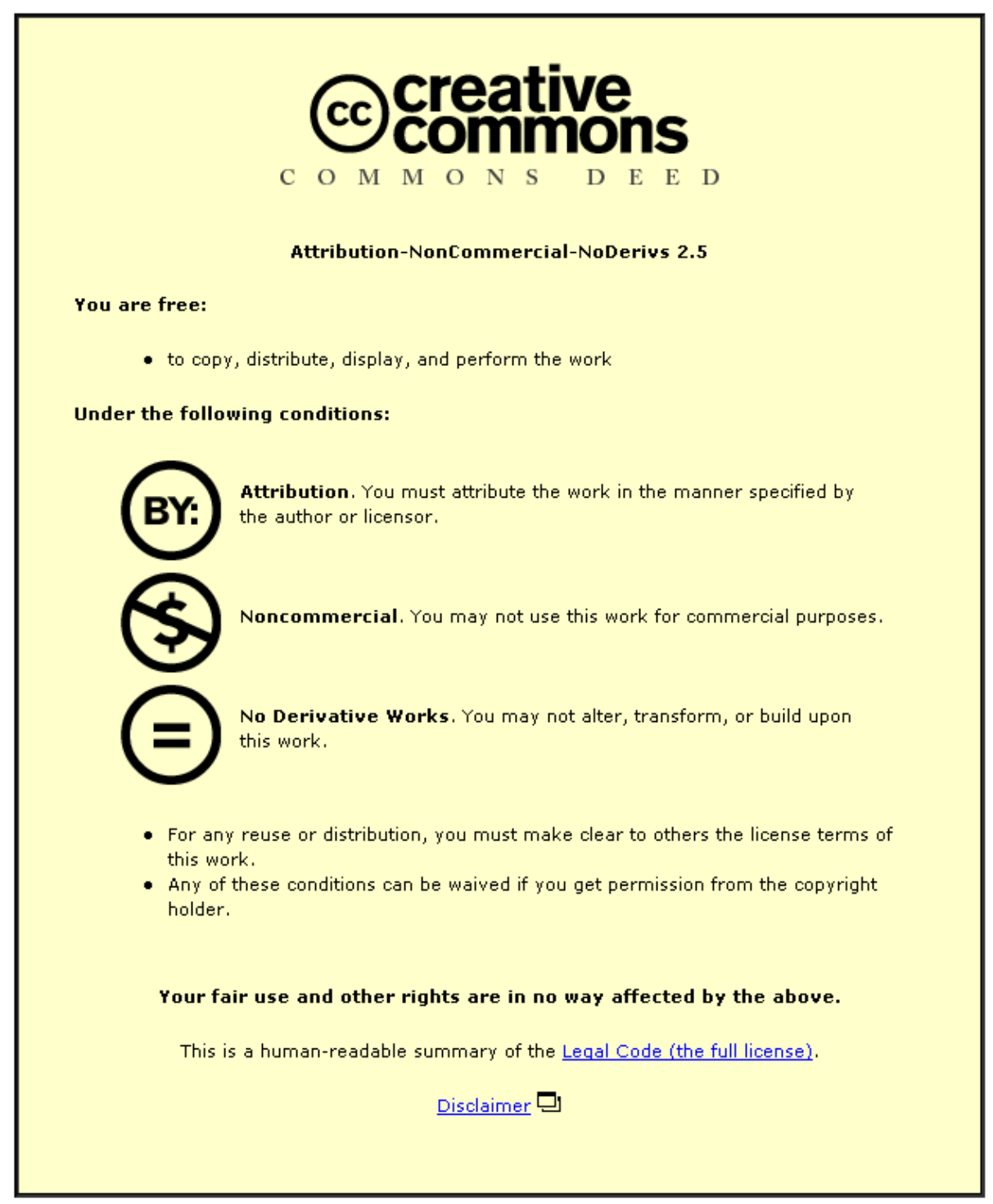

For the full text of this licence, please go to: http://creativecommons.org/licenses/by-nc-nd/2.5/ 


\title{
Knowledge transfer in IT offshoring relationships: The roles of social capital, efficacy and outcome expectations
}

\begin{abstract}
Information technology (IT) development in global organisations relies heavily on the transfer of tacit and complex knowledge from onshore units to offshore subsidiaries. A central concern of such organisations is the development of social capital, which is known to facilitate the smooth transfer of knowledge. However, only a few studies in IS research have explicitly examined the role of social capital for knowledge transfer in an IT offshoring context. In this paper we argue that such knowledge transfer mechanisms can be understood better by considering social capital in concert with knowledge senders' efficacy and outcome expectations, two of the potentially key motivational drivers of knowledge transfer. We develop our arguments through a qualitative case study of a large German multinational company. German IT developers in this firm provided in-depth accounts of their experience with offshore colleagues in an Indian captive subsidiary unit. Drawing on our analysis, we develop a model that depicts the influence of social capital, efficacy and outcome expectations on onshore IT developers' ability and willingness to transfer knowledge to offshore colleagues. Through the model we also explain how social capital, efficacy and outcome expectations are interrelated and generate three interlocked, self-reinforcing circles of knowledge transfer success in IT offshoring relationships.
\end{abstract}

Key words: IT offshoring, knowledge transfer, social capital, efficacy, outcome expectations 


\section{INTRODUCTION}

In many global organisations, IT software development is increasingly undertaken by teams comprising both onshore and offshore members. Effective transfer of knowledge from onshore IT units to offshore subsidiaries is central to the success of such software development projects (Bhagat et al., 2002; Chua \& Pan, 2008). Although extant IS research has shown how onshore to offshore knowledge transfer is impeded by several characteristic IT offshoring-related factors, such as geographical distance and cultural boundaries (e.g. Herbsleb \& Grinter, 1999; Levina \& Vaast, 2008), very few IS studies have examined the crucial role of social capital in the knowledge transfer process (for an exception, see Rottman, 2008). Further, two of the potentially key motivational drivers of knowledge transfer from onshore IT headquarters to offshore IT locations - the efficacy beliefs and outcome expectations of onshore IT development groups - have received scant attention in IS research. In this paper, we will demonstrate how knowledge transfer mechanisms in IT offshoring relationships can be understood better by considering social capital alongside efficacy and outcome expectations. We also show how the combination of these two perspectives provides a deeper understanding of two important constituents of the knowledge transfer process, namely onshore IT developers' ability to transfer knowledge and their willingness to do so. Knowledge transfer ability and willingness have previously been defined as 'disseminative capacity' and are seen as important preconditions for actual knowledge transfer from the knowledge provider (Minbaeva \& Michailova, 2004). Going beyond a linear perspective, we arrive at a more comprehensive view of how social capital, efficacy and outcome expectations are interrelated during IT offshoring projects, and how they generate three interlocked, self-reinforcing circles of knowledge transfer success, involving both knowledge transfer ability and willingness.

In global multinational companies (MNCs), transfer of knowledge from onshore IT teams to offshore IT teams has for long been linked to cost advantages, standardisation, development of innovative products and services and to the overall success of the IT offshoring relationship (Hawk et al., 2009; Leonardi \& Bailey, 2008; Oshri et al., 2008; Zimmermann \& Ravishankar, 2011). Although knowledge transfer from offshore to onshore locations is also increasingly relevant for multinational organisations (see Eden, 2009), in settings such as ours where onshore IT groups clearly have greater technical expertise and experience, the unidirectional process of 
knowledge transfer from onshore to offshore units deserves separate and special attention. In fact, such a process of onshore to offshore knowledge transfer may very well help set the stage for successful reverse (offshore to onshore) knowledge transfers in the future. We therefore focus squarely on the unidirectional process of knowledge transfer from onshore IT groups that possess higher-levels of expertise and experience to offshore IT groups that possess lower-levels of expertise and experience.

While being essential, knowledge transfer is particularly challenging in IT offshoring settings. This is because such IT offshoring arrangements create all of the classical barriers to knowledge transfer described by Szulanski (1996) - causal ambiguity, low absorptive capacity, and arduous relationships between onshore and offshore units. In the case of offshored IT application development projects, very complex domain knowledge, which is often uncodified, tacit and context dependent, needs to be transferred (Dibbern et al., 2008; Herbsleb \& Grinter, 1999; Levina \& Vaast, 2008). This challenge gets further intensified in contexts of low absorptive capacity and high employee attrition in the offshore unit. For instance, research suggests that some offshore units can have a limited ability to understand the consequences of software errors and can also suffer from a high turnover of IT developers, making effective knowledge transfer even more difficult (Dibbern et al., 2008). In addition, the relationship between onshore and offshore units tends to be constrained, in particular through spatial and cultural distance (Cummings, 2011; Gregory, 2010; Ravishankar et al., 2010; Zimmermann, 2011), differences in organisational and national contexts (Levina \& Vaast, 2008), and status differences (Metiu, 2006, Ravishankar et al., 2013). These conditions can constrain onshore IT developers' ability and motivation to transfer knowledge to their offshore counterparts. Given these constraints, the presence of social capital plays a particularly important role in knowledge transfer within the offshoring context.

Social capital is typically defined as the resources embedded within, available through, and derived from an individual's or social unit's network of relationships (Nahapiet \& Ghoshal, 1998: 243). The nature of networks between organisational units can facilitate or hinder knowledge transfer between these units, by affecting employees' ability and their willingness to transfer knowledge (i.e., their disseminative capacity). For instance, trust and shared organisational identity increase employees' willingness to engage in knowledge transfer across country 
borders. Close and frequent interactions between offshore and onshore IT teams are particularly important for transferring tacit forms of knowledge, since such meetings facilitate a detailed articulation of knotty problems and allow for two way communications leading to multiple feedback loops (see Hansen, 1999).

We will demonstrate that onshore IT teams' willingness to transfer knowledge is also affected by whether they believe they are able to transfer the knowledge, and by their expectation that the transfer will lead to desirable outcomes. Such 'efficacy beliefs' and 'outcome expectations' are important motivational determinants of behaviour, as explained by social cognitive theory (Bandura, 1997; Bandura \& Wood, 1989). More precisely, 'self-efficacy' is the belief in one's capabilities to organise and execute courses of actions required to manage prospective situations (Bandura, 1997). At the group level, 'collective efficacy' refers to the group's shared belief in its conjoint capabilities to organise and execute the courses of action required to produce given levels of attainment (Bandura, 1997: 477). Both forms of efficacy influence individuals' intention to execute the behaviour, their effort and persistence with that behaviour, and finally their mastery of the behaviour. Accordingly, a few studies have shown that knowledge senders are more likely to engage and persist in knowledge transfer behaviours, if they believe they have the ability to contribute valuable knowledge and to communicate their knowledge effectively (e.g. Hsu et al., 2007; Kang et al., 2010). SCT also holds that if behaviours (such as knowledge transfer activities) are successful, this can reinforce efficacy beliefs and subsequent effort in such behaviours, leading to self-reinforcing spirals (Lindsley et al., 2005).

Outcome expectations, in turn, refer to the expected consequences of one's behaviour. If these outcomes are regarded as attractive, they motivate behaviour that is believed to lead to these outcomes (Ajzen \& Fishbein, 1980: Bandura, 1997: 125). For example, the willingness to transfer knowledge can be increased by expected positive contributions to the performance of the organisation (Bock et al., 2005). IS research on efficacy and outcome expectations in knowledge transfer is still at a nascent stage, and it has also not paid much attention to the IT offshoring context. Moreover, only a few researchers combine the study of efficacy or outcome expectations with aspects of the social capital lens when examining knowledge transfer. This combination of the two perspectives helps provide a deeper 
understanding of the mechanisms of knowledge transfer, with regard to onshore IT developers' ability to transfer knowledge as well as their willingness to do so.

In the following sections, we will further our arguments by reviewing prior literature on knowledge sharing and knowledge transfer that addresses the roles of social capital, efficacy beliefs and outcome expectations. Throughout, we will distinguish between knowledge transfer ability and willingness. We then present results from a qualitative case study of a large German electronics MNC. German IT developers in this firm provided in-depth accounts of their experience with offshore colleagues in an Indian captive subsidiary unit. Drawing on our analysis, we build a model that explains how social capital, efficacy and outcome expectations can affect onshore IT groups' ability and willingness to transfer knowledge to offshore units, and how these factors are interrelated. We also explain how our study can offer new insights for IS research on IT offshoring and knowledge transfer, and to IT offshoring practitioners.

\section{THEORETICAL BACKGROUND}

Knowledge transfer refers to the process through which one network member is affected by the experience of another (Argote \& Ingram, 2000: 151). Knowledge transfer thus describes a unidirectional process that manifests itself through changes of knowledge in the recipient unit (Argote \& Ingram, 2000: 15). Knowledge transfer is thus part of knowledge sharing, which describes a bi-directional or multidirectional process whereby two or more parties contribute knowledge (Gupta \& Govindarajan, 2000). There is now a growing body of work that demonstrates the importance of social capital for knowledge transfer processes in various organisational contexts. Following Nahapiet and Ghoshal (1998), scholars commonly distinguish between the structural, relational, and cognitive dimension of social capital.

\section{Structural dimension}

The structural dimension refers to the overall pattern and configuration of connections between actors (Nahapiet \& Ghoshal, 1998). With regard to this dimension, the number of ties an actor has to other network members, the configuration of the network (e.g. hierarchy and connectivity) and network stability are particularly important for an actor's ability to access and process knowledge (Gupta \& Govindarajan; 2000; Hansen, 1999; Inkpen \& Tsang, 2005). Evidently, it is 
easier to achieve high connectivity within organisations than with external organisations, for example through personnel transfers (Inkpen \& Tsang, 2005). However, in an IT offshoring setting, geographical and cultural boundaries make it harder to create social ties (Gregory, 2010) even when subsidiary units of the same organisation are involved. Moreover, high employee turnover at the offshore unit often weakens the stability of the social network created between onshore and offshore IT teams (Dibbern et al., 2008; Rottman, 2008). As mentioned earlier, close and frequent interactions are particularly important for transferring tacit knowledge, which requires socialisation (Nonaka, 1994) through two-way interactions (Hansen, 1999). In offshoring settings, spatial and cultural distances limit such interactions, and therefore constrain IT developers' ability to transfer the necessary tacit knowledge (Dibbern et al., 2008).

\section{Relational dimension}

The relational dimension of social capital refers to assets created and leveraged through personal relationships (Nahapiet \& Ghoshal, 1998). The four important facets of relational capital commonly highlighted are trust and trustworthiness, norms and sanctions, obligations and expectations, and identity and identification (Nahapiet \& Ghoshal, 1998). Trust, built on an assessment of the offshore counterpart's benevolence and competence (Inkpen \& Tsang, 2005; van Wijk et al., 2008) can be crucial for onshore IT teams' willingness to transfer knowledge (Jarvenpaa \& Leidner, 2002; Williams, 2011). Trust is easier to establish with members of the same organisation, where hostile competition and opportunism are less prominent, than in trans-organisational networks (Inkpen \& Tsang, 2005). However, it is harder to build trust across the geographical and cultural boundaries that exist even within company-internal IT offshoring collaborations (Winkler et al., 2008). Moreover, 'commitment trust', the expectation that the relationship will lead to mutual benefits (Newell \& Swan, 2000: 1295) can be impeded by onshore groups' belief that the transfer of tasks to the offshore destination threatens their own careers. Onshore IT teams may thus fear 'building their own guillotines' (Rottman, 2008: 41) through knowledge transfer, and may use scapegoating (Cohen \& El Sawad, 2007) and 'closure' strategies to enhance their own status (Metiu, 2006).

'Norms' represent a degree of consensus in a social system. Strong cooperation norms, for example, can create expectations of openness and 
teamwork, which facilitate individuals' willingness to share knowledge (Nahapiet \& Ghoshal; 1998). Knowledge transfer can also be motivated by other expectations, such as those of reciprocity.

'Identification' is the condition where values or standards of the individual merge with those of a group. A sense of shared identity creates concern for collective outcomes and therefore motivates individuals' effort in transferring knowledge to help enhance the groups' outcomes (Nahapiet \& Ghoshal, 1998: 256). Shared norms, expectations, and identification are all easier to establish with members of the same organisation (Inkpen \& Tsang, 2005). However, in IT

offshoring settings, even within an organisation, shared norms, expectations and identification are encumbered by cultural differences, geographical distance, and contextual boundaries, for instance, between global headquarters and offshore subsidiaries (Levina \& Vaast, 2008).

\section{Cognitive dimension}

The cognitive dimension of social capital refers to the resources within relationships that provide shared representations, interpretations and systems of meanings (Nahapiet \& Ghoshal, 1998, p. 244). These can be part of a shared vision and culture within an organisation (Inkpen \& Tsang, 2005), which provide bonding mechanisms and shared frames of reference. A shared contextual understanding is central, in particular, to the transfer of tacit knowledge. In IT offshoring relationships, the crossing of national boundaries, over-reliance on virtual interactions and restrictions on face to face communication are clear barriers to overcome in this regard (Vlaar et al, 2008). To provide a typical example, being unaware of their offshore colleagues' limited knowledge of the software environment makes it hard for onshore IT developers to write software specifications that offshore teams can comprehend and code into reliable software programs (Dibbern et al., 2008; Herbsleb \& Grinter, 1999; Herbsleb \& Moitra, 2001).

From the above review of the literature, it is evident that the presence of social capital influences onshore IT teams' willingness and their ability to transfer knowledge. Whilst the structural and the cognitive dimension of social capital appear to be most relevant for their ability to transfer knowledge, the relational dimension can be particularly important for their willingness to do so. However, there are other 
important motivational drivers of knowledge transfer that social capital theory does not capture. In the following, we will review the two of them that we are interested in, namely, efficacy and outcome expectations.

\section{Efficacy and Outcome expectations}

As outlined in the introduction above, social cognitive theory (SCT) (Bandura, 1997) provides important insights into the motivational drivers of knowledge transfer behaviours, which are not accessible by drawing on the notion of social capital alone. In our study, we therefore propose to apply the social capital lens in concert with the elements of SCT. Although collective efficacy and outcome expectations have not been applied explicitly to research on knowledge transfer, they have been shown to affect knowledge sharing in various organisational contexts. Given that knowledge transfer is an element of knowledge sharing, this prior evidence supports our claim that efficacy and outcome expectations can play a role in knowledge transfer. We briefly review relevant findings from this stream of literature below.

Studies show knowledge sharing efficacy, defined as the belief in one's capability to contribute valuable knowledge, to be closely associated with knowledge sharing intentions (Lin, 2007), with actual knowledge sharing behaviours (Hsu et al., 2007; Kuo \& Young, 2008) and in the use of organisational knowledge management systems (KMS) and repositories (Kankanhalli et al., 2005; Lin \& Huang, 2008). In line with SCT, researchers suggest that higher knowledge sharing efficacy motivates employees to share knowledge, increase their effort, and persevere in knowledge sharing. However, researchers have so far only inferred these mechanisms from quantitative associations between the variables, rather than demonstrating them empirically through qualitative analyses.

Outcome expectations, the other notion put forward by SCT has also been considered as important in research on knowledge sharing. In virtual communities, Hsu et al. (2007) found that knowledge sharing is affected by personal outcome expectations, such as prospects of gaining respect and strengthening social ties. Similarly, Lin and Huang (2008) suggest that expectations of personal outcomes, for example, image and reward outcomes, crucially influence employee usage of organisational KMS. In contrast, Chiu et al. (2006) argues that knowledge sharing in virtual communities is associated more with community-related outcome expectations, rather than personal outcome expectations. Some recent research 
suggests that both types of outcome expectations affect knowledge withholding behaviours (Lin \& Huang, 2010).

The importance of outcome expectations for knowledge sharing is underscored by other studies that, however, do not refer to this concept explicitly. For example, studies of commercial firms have examined outcome expectations in terms of extrinsic motivational factors that affect knowledge sharing, such as organisational rewards and reciprocity (Bock et al., 2005; Kang et al., 2010; Kankanhalli et al., 2005; Lin, 2007), and intrinsic motivational factors, such as a sense of self-worth (Bock et al., 2005), enjoyment in helping others (Kankanhalli et al., 2005; Lin, 2007), and improving productivity and work processes (Bock et al., 2005). Of these, all apart from organisational rewards were consistently associated with knowledge sharing behaviour (Kang et al., 2010; Kankanhalli et al., 2005) or intentions (Bock et al., 2005; Lin, 2007). These quantitative findings lend further support to our argument that outcome expectations can affect onshore IT teams' willingness to transfer knowledge.

Some studies on knowledge sharing demonstrate the influence of social capital alongside efficacy or outcome expectations (see Chen \& Hung 2010; Chiu et al., 2006; Hsu et al., 2007; Kang et al., 2010; Kankanhalli et al., 2005; Wasko et al., 2005). Although this stream of research does not explicitly address the linkages between social capital and self-efficacy or outcome expectations, several links become apparent, which supports our claim that these factors should be considered in conjunction with each other. Firstly, prior research highlights that knowledge sharing is motivated by expectations of reciprocity, strengthened ties and friendship (Bock et al., 2005; Hsu et al., 2007; Kang et al., 2010; Kankanhalli et al., 2005; Lin, 2007). These outcome expectations can be regarded as elements of the relational dimension of social capital. Such expectations of relational outcomes are also seen to be reinforced by knowledge sharing. This implies that outcome expectations strengthen relational capital via their effect on knowledge sharing. Secondly, the influence between outcome expectations and relational capital may be mutual, considering Kang et al.'s (2010) evidence that expected reciprocity depends on the strength of social ties. These considerations highlight the need to detail the interrelations of social capital with efficacy and outcome expectations when examining knowledge transfer in IT offshoring relationships. Following these 
reflections, we present a qualitative case study that investigates whether and how social capital, efficacy beliefs, and outcome expectations can influence onshore IT developers' ability and willingness to transfer knowledge to offshore colleagues. We distinguish between the structural, relational, and cognitive dimension of social capital, and we consider social capital's links with efficacy and outcome expectations.

\section{METHODS}

We carried out a qualitative case study to solicit respondents' accounts of knowledge transfer mechanisms in their particular offshoring setting. This method is considered to be one of the most suitable for exploring under-researched phenomena, and for providing an in-depth analysis of complex socio-psychological mechanisms in a real life context (Yin, 2009), such as those involved in onshore-offshore knowledge transfer.

\section{Data collection}

The research was set in a large German electronics firm that has close to 300,000 employees worldwide and over 18,000 in India, where software development sites have existed since the early 1990s. The company's explicit strategy is to offshore further IT tasks to Indian subsidiaries continuously and at a rapid pace, which necessitates repeated, intensive, uni-directional, onshore to offshore knowledge transfer. For this purpose, German IT developers have to share their existing expertise with Indian colleagues. In the main, German respondents are therefore the knowledge providers or senders, whilst Indian colleagues are the knowledge recipients.

Given the focus of our study on the ability and willingness of onshore IT employees to transfer knowledge, the first author conducted 30 interviews with German respondents at the German onshore headquarters. All but one of the respondents were male, which is typical for this industry in Germany. The respondents were charged with the development of software and hardware for automotive car engines. Two departments were included, one responsible for developing electronic control units, the other for the electronics of automotive safety systems. The respondents were part of several 'groups' in these departments (see Appendix A). All apart from four respondents held leadership positions, either as 
group-, team-, project- or project section leader. The group leaders acted mainly as managers, responsible for the offshoring strategy and capacity planning. All other positions involved hands-on collaborative IT development. Eight respondents were assigned the additional role as coordinators for the India collaboration. In this function, they were responsible for organising the offshore capacity and budget and for dealing with any interpersonal problems, such as intercultural difficulties. In each department, one respondent held a staff position as coordinator of the whole department's India collaboration. The respondents varied regarding their length of experience in working with the Indian subsidiary, ranging from one to 10 years, with the exception of one respondent who looked back on 18 years of experience and another who had only worked with Indian colleagues for three months as an expatriate in the Indian unit. The safety systems department had been collaborating with India for a shorter time and therefore, the respondents in this department had relatively less experience of working with Indian counterparts (between one to three years). The tasks delegated to India ranged from simple coding and software maintenance tasks to more comprehensive and innovative function development tasks. The German IT developers interacted with Indian colleagues directly rather than through mediators, and were responsible for providing software specifications and transferring the required knowledge. These respondents were therefore well placed to share their first-hand experience of transferring complex knowledge to Indian colleagues.

Indian counterparts were generally described as 'young' in comparison to German employees. However, respondents pointed out that their Indian colleagues' tenure and work experience varied a lot, ranging from 'freshers' to 'experienced colleagues' who had been with the company for many years. These differences were commonly seen as important reasons for differences in performance and for the strength of the relationship. However, most Indian colleagues had visited the German office, not long after their recruitment, for training purposes.

The interviews were conducted in German and each interview lasted for about an hour. All the interviews were tape-recorded and transcribed in German. The interviewees were asked the same main questions, whilst their order was adjusted depending on the flow of the conversation. Additional questions were posed to explore topics that were mentioned spontaneously. Such emergent topics were also included in subsequent interviews. The initial questions concerned the number of 
German and Indian colleagues in the respondent's project, the length of their collaboration, and the tasks of German and Indian colleagues. As part of a broader inquiry on offshoring relationships, respondents were further requested to describe their collaboration and relationship with Indian colleagues. They were asked to judge how well knowledge was transferred from onshore to offshore, which typically revealed efficacy beliefs and difficulties in transferring knowledge. Additionally, we also discussed team member roles, German-Indian team identity issues, trust, competition, conflicts, friendliness and the overall team environment. These questions were particularly helpful in theorising the links between social capital and knowledge transfer ability and willingness. The respondents were further asked to rate the performance outcomes of their respective German-Indian projects, and to describe the advantages and disadvantages that the transfer of tasks to India created for the firm, the transnational team, and for the German team members. We also asked the respondents to evaluate and assess the outcomes of IT offshoring, including work efficiency, cost savings, intercultural experiences, and likely consequences for tasks, careers and jobs. The answers to these questions were helpful in understanding how the respondents' efficacy beliefs and outcome expectations motivated knowledge transfer behaviours.

The responses were often candid, which was most likely facilitated by the respondents' familiarity with the interviewer and trust in the interviewers' impartiality. The interviewer (first author) is a German national and a former employee of the firm, and may therefore have been regarded as an insider to the firm. However, the first author has been a full-time academic since 2007, and therefore does not have any potential interest in or influence on respondents' careers.

\section{Data analysis}

The empirical data was analysed through an iterative process of comparison between emergent findings and theoretical concepts, in line with Eisenhardt's (1989) classic suggestions for developing theory from case study research. Some key concepts emerged from the salient comments of interviewees, and were explored systematically in the post-interviewing phase. To illustrate, the importance and difficulties of knowledge transfer, and the crucial role of interpersonal relationships as facilitators of knowledge transfer were mentioned spontaneously by most interviewees. When consulting the literature, the reported descriptions of 
relationships fitted well with the three-fold structure of social capital. Moreover, striking differences became apparent in our respondents' judgments about whether knowledge transfer was possible, which resonated with the notion of differing efficacy beliefs. The interviews also threw light on clearly contrasting evaluations of knowledge transfer outcomes, for example regarding workload, tasks, and job security, which matched the concept of outcome expectations. The role of efficacy beliefs and outcome expectations as motivational drivers was mentioned specifically by some respondents, but was also inferred by comparing contrasting reports. Having tentatively chosen these theoretical concepts to explain the mechanisms of knowledge transfer, we captured them in a preliminary model that described the influence of social capital, efficacy, and outcome expectations on knowledge transfer ability and willingness. Node lookups in NVivo 8 software then served to scan all interviews for supporting and contradictory evidence (see Appendix B for Key NVivo nodes). This evidence was summarised alongside the key concepts (see Appendix C). A comparison between contradictory answers revealed that contextual factors, such as turnover levels amongst Indian colleagues, length of experience in the collaboration, and managerial strategies for future tasks onshore and offshore, explained differences, which helped to confirm and expand the preliminary model. A deeper interpretation was possible through a synopsis of the perceived linear effects, which revealed three circles of influence. To take one example, many interviewees explained how trust and shared identity influenced their willingness to transfer knowledge and, consequently, their knowledge transfer effort. At the same time, they also noted that the more effort they put into knowledge transfer, the more it strengthened the team's identity and helped improve trust. Clearly, these effects implied a circular relationship involving trust/identity, willingness, and effort.

We revisited the summaries and key quotes, and travelled back and forth iteratively from the data to the literature on social capital, efficacy, and outcome expectations, until the emerging model was fully supported by both data and theory and no further modifications seemed valuable. We thus developed our refined model and also ensured that a reasonable level of theory-data-model alignment was reached.

\section{FINDINGS}


The reports of our participants highlighted that social capital influenced knowledge transfer through all three of its dimensions. The structural dimension impinged upon the German respondents' knowledge transfer ability, the relational dimension affected both willingness and ability, and the cognitive dimension was crucial for knowledge transfer ability. It also became clear how the three dimensions were interrelated and how particular characteristics of the IT offshoring setting, namely spatial and cultural distance, organisational boundaries, high turnover levels of offshore colleagues and the need to transfer tacit and complex knowledge impeded social capital on all three dimensions. At the same time, these offshoring characteristics created a strong need for developing social capital.

\section{Structural dimension}

With regard to the structural dimension of social capital, respondents' reports demonstrated that the strength of network ties and network stability were important reasons for both difficulties and ease of knowledge transfer. In our offshoring setting, the strength of ties and relationship closeness were impeded by the physical distance between onshore and offshore IT teams. Thus, getting to know Indian colleagues in person and working alongside them on training visits in Germany or India were, beside frequent phone calls, seen as important conditions for transferring knowledge, in particular because they helped to develop open communication, trusting relationships, and a team identity. This implies that the structural dimension of social capital affected knowledge transfer ability through its effect on the relational dimension:

The largest part of the knowhow transfer really happened when the [Indian]

colleagues were over here. ... Once you got to know the colleagues, it is a completely different togetherness, only then you have the chance of becoming a team. (Respondent 25, Team leader)

and:

You need very close personal contact... It has cost us a lot of time and also many trips to India. We are typically over there once in three months for about a week, but it has been worth it. (Respondent 27, Group leader)

Visits and frequent informal interactions were also vital for developing an understanding of the Indian IT developers' knowledge requirements and creating a shared contextual understanding, which are part of the cognitive dimension of social 
capital. Network instability, due to high employee turnover at the Indian unit, was a major problem for developing strong ties. Somewhat ironically, our respondents claimed that Indian colleagues' visits to the onshore German location played a part in destabilising the onshore-offshore team networks, since such visits qualified these Indian counterparts to take on more demanding roles. According to our respondents, such 'qualified' Indian colleagues often quit their team soon after their return to India. While it is hard to verify whether it was their newly developed ability to take on demanding roles that really led Indian colleagues to leave their teams, these comments of our German respondents clearly underscores the challenges of network instability triggered by offshore employee turnover. Neither the number of network ties nor network configuration appeared to be issues for knowledge transfer. This is not surprising, given that knowledge was transferred between well-defined partners in small work teams rather than larger networks.

\section{Relational dimension}

The interviews revealed that the relational dimension of social capital was fundamental for the German IT developers' ability and their willingness to transfer knowledge. German respondents felt that high levels of mutual trust and a feeling of shared team identity were necessary to communicate freely with the Indian colleagues. Such open communication was particularly essential where the transfer of tacit knowledge was involved. Yet, according to our respondents, it took some time for the Indian colleagues to open up and communicate freely. Indian colleagues did not typically dare to voice their questions openly at the start of collaborative projects, but this changed dramatically after short visits, which facilitated the creation of a more trusting relationship. This experience of the German respondents obviously resonates with some of the early knowledge transfer literature: the creation of a trusting relationship is essential for meaningful two way interactions and feedback loops between senders and receivers of knowledge, which then enables the transfer of complex and tacit knowledge (see Hansen, 1999).

Visits were further necessary for developing a shared team identity, as indicated above. Developing a team identity also emerged as important for the German respondents' willingness to transfer knowledge. As fellow team members, the German side felt responsible for enabling their Indian colleagues to perform well, and put effort into knowledge transfer: 
It is not that I do a specification at some stage, then send it to India and tell them: 'You should be finished by this and that time, and when you have finished, we will look at it again and if it then does not work, I will beat you with a stick', so to say. Instead, we have regular contact, and part of this is also a certain support with regard to problems. I don't leave anyone on their own. (Respondent 21, Team leader)

However, the understanding of the German-Indian collaboration as team work was not shared by all German employees. Contractually, Indian colleagues were defined as company-internal suppliers and German colleagues as internal customers of software products. Respondents explained that some Germans preferred to interpret this contract in a way to treat the Indians as mere suppliers rather than fellow team members, because this allowed them to stipulate results without sharing the responsibility. These German IT developers were then free to keep knowledge transfer tasks to the necessary minimum, rather than engaging in extra effort:

That's also why some colleagues prefer to have a customer-supplier sort of relationship. Then you do not have to deal with each other so closely, and it also becomes easier to say, in case problems arise: 'The [Indian] colleague (the supplier) has not delivered I couldn't do anything. ...We would have done this much better, over here [in Germany].' The dissociation is then much easier. ... and it is harder to motivate [Germans] to transfer know how, to enable [Indian] people, or give them advice on how they could do things better... You rather tend to say: 'You supplier, just do it, I'm not interested in the way you do it, but I want the following result.'

(Respondent 25, Team leader)

This refusal to build relational capital with Indian colleagues cannot be explained by social capital theory alone, but only by looking additionally at the German side's knowledge transfer efficacy and their outcome expectations, as described later on. Respondents also explained that some Indian colleagues were led to believe by the supplier-customer arguments that they had to fulfil the German colleagues' demands unquestionably, and therefore sought to avoid making a bad impression by not asking for clarifications about tasks from onshore colleagues, even when such information was extremely important for taking the project further. Such periodic breakdowns of communication had additional negative effects on the Germans' ability to transfer knowledge, especially of the complex and tacit kind. 


\section{Cognitive dimension}

The interviews demonstrated that the cognitive dimension of social capital impinged upon the German respondents' ability to transfer knowledge, especially complex and tacit knowledge. Due to their different organisational and national environments, Indian and German colleagues did not have the same contextual understanding of head office strategies, customer requirements, the software system domain, and the application domain. Our German respondents felt that Indian colleagues often failed to fully appreciate how the software product they were developing would fit into the final product. To clearly comprehend their software product's role in the final product being developed (i.e., an automotive engine), the Indian IT development teams needed to possess high levels of tacit knowledge about the workings of an automobile, which according to the German respondents, they clearly did not.

We actually bring that with us, from the cradle. Because we become familiar with a car from a very young age. ... One laughs about Indians sitting in a car and not even being able to distinguish automatic from manual gears. ... Over here, that's easy.

Well, you just learn it at some stage and know it, and then it becomes taken for granted knowledge. But for our Indians, who usually simply sit on the motorcycle or so, and not in a car, they simply don't know that. (Respondent 15, Project member)

In one sense this quote brings into sharp focus the tendency of some onshore IT developers to engage in broad and simplistic generalisations about the abilities of all offshore colleagues. But from a knowledge transfer point of view, the possible lack of shared contextual understanding between onshore and offshore colleagues did affect the transfer of tacit knowledge. Such tacit knowledge was very hard for the German side to encode and equally hard for the Indian side to decode. In many instances, the software specifications written by the German respondents contained insufficient information.

The problem is that, over here, we have the background and take many things for granted, because everyone here knows it. But it does not occur to you that India has never heard of it. You only notice this if there is a query somewhere, or if something goes wrong. (Respondent 7, Team leader)

German respondents therefore had to learn what background information had to be included in their highly detailed software specifications: 
You can't expect that we... pass over a kind of draft where we simply say: 'that must be obvious, that's enough for me'. I can create a function out of that, an Indian person can't. Because he lacks that system background. They don't even drive a car, after all. (Respondent 10, Group leader)

The differences in contextual understanding became obvious in many cases when the Indian side had misinterpreted German specifications, which led to faults in the final software product:

We have some examples here, where we have delivered faulty software [to the end customer] ... which had, however, been developed in India one to one according to our specifications. We had written it in one way and one could interpret it in another way. ... This is simply the question: Who's fault is it now? The one's who has done the specification, or the one's who has not questioned it? (Respondent 18, project member)

The difficulties of knowledge transfer created through the cognitive dimension of social capital underscore the importance of the other two dimensions. In order to develop a shared contextual understanding (cognitive dimension), it was necessary to transfer contextual, complex, and tacit knowledge, and this was only possible if sufficient visits had taken place (structural dimension) allowing the respective German and Indian groups to develop a trusting relationship and a team identity (relational dimension).

The influence of the three dimensions of social capital on knowledge transfer ability and willingness is captured in the upper part of Figure 1. As explained above, tie strength and network stability, as part of the structural dimension of social capital, supported the German side's ability to transfer knowledge, both directly as well as by allowing the relational aspects (trust and shared identity) to grow. Strong trust and identity reinforced the German respondents' ability and also their willingness to transfer knowledge. Shared contextual understanding, in turn, as part of the cognitive dimension, was supported by trust and team identity, and was another enabler of knowledge transfer. The figure also illustrates the roles of efficacy and outcome expectations, which we explain in what follows.

Insert Figure 1 about here 


\section{The roles of efficacy and outcome expectations}

Our results also revealed that collective efficacy and outcome expectations were important motivational factors of knowledge transfer, besides social capital. It also became clear that they were interconnected with social capital, and that they were tied to certain characteristics of the IT offshoring setting.

\section{Efficacy}

One of the main on-going concerns of the German IT teams was whether they would be able to transfer knowledge to offshore colleagues and raise the offshore teams' expertise levels to the required standards. Our respondents had mixed beliefs about their team's abilities in this regard. Such mixed beliefs about knowledge transfer abilities are reflective of what has been termed in the literature as variations in collective efficacy beliefs (Bandura, 1997).

From our interviews, it was apparent that some of the German respondents' beliefs about their ability to transfer knowledge (i.e., their collective efficacy beliefs) were closely linked to their perceptions of the Indian counterparts' ability to absorb and process the required knowledge, i.e. their absorptive capacity. Due to the obvious limits of contextual understanding (e.g., limited knowledge of the workings of the final product), absorptive capacity on the Indian side was felt to be low in many cases. Some of our respondents therefore believed that they would be unable to achieve sufficient levels of knowledge transfer within the time frame of a given project. Respondents with such beliefs were less willing to take part in knowledge transfer activities, and therefore put little effort into knowledge transfer activities, even when they had to. As a respondent commented tersely:

Well, that will never work, why should I put a lot into it. (Respondent 9, Project section leader)

This link from efficacy to knowledge transfer willingness is indicated in Figure 1. Other respondents, however, stressed that it was possible to overcome initial hurdles of knowledge transfer, as long as sufficient effort was spent on knowledge transfer at the start of collaborative projects.

... [German] colleagues also have to be aware that it takes some time until the collaboration works smoothly, and that you have to approach people [in India]... and this takes time. ... You easily have to allow for six to twelve months, until you see the 
benefit. Until the colleague also realises: 'OK, something is coming back here, this really is useful for me.' (Respondent 4, Project leader)

The differences in respondents' efficacy beliefs also need to be seen in the context of the high levels of employee turnover on the Indian side, which many our respondents claimed was an important issue that needed addressing. Some of our respondents had worked with Indian teams where personnel movements and changes were minimal. This allowed them to establish stable working relationships with colleagues in the Indian team and to develop sufficient levels of expertise. The experience of some of our other respondents was very different. They had initially spent considerable effort in training Indian colleagues, developing relationships and a shared contextual awareness required for knowledge transfer, only to find out soon afterwards that these Indian colleagues had left their team or even the firm. They were frustrated because their efforts were wasted. They no longer believed that knowledge transfer was possible, and therefore chose to limit the effort they put in knowledge transfer activities:

There is of course also the weariness factor. ... There was simply the opinion: "Well, why should I explain it to him now, once again. He will just be gone anyway, in six months' time.' (Respondent 15, Project member)

As mentioned before, one way of limiting one's knowledge transfer effort was to treat Indian IT developers as mere suppliers rather than fellow team members. In this manner, knowledge transfer efficacy affected the relational dimension of social capital (see arrow on the extreme left in Figure 1, leading directly from efficacy to the relational dimension of social capital).

Efficacy was also important as far as intercultural communication was concerned. German respondents varied in their belief in their capability to overcome intercultural communication barriers, such as speaking English, or understanding what they felt was the Indians' indirect communication style. This communicationrelated self-efficacy influenced the extent to which the German IT developers were willing to engage in intercultural communication, which was of course a part of knowledge transfer (see Figure 1, arrow from efficacy to knowledge transfer willingness).

First of all, I think that in a team which has communicated ... in high German before or even better: in Swabonian dialect - the language barrier is an issue, of course. I now have to explain to an Indian colleague what he should do. I can't see him, I only 
have his e-mail, and then he writes back to me some kind of - phrases - in English. I yet have to guess what is written, the wording, as well ... I think we simply did not have the cultural background understanding: ... 'How do I have to interpret this now? What is the Indian colleague actually waiting for?‘. (Respondent 12, Project leader) and

With the Indian colleague, I have ... to ask actively whether everything has been understood, and the first time, I actually have to ask several times whether everything is ok, and give him the opportunity to ask any questions, because he would never ask a question on his own accord. I have to also know how to interpret his answers. If an Indian colleague says 'I will try', then I have to know that this means he sees no chance, but does it anyway to do me a favour, but he does not even see a point to start. By contrast, if a German says 'Yes, I will try', then I will assume that at least a 90\% solution will come out of it. (Respondent 29, Team leader)

Beliefs about their inter-cultural communication ability also influenced the extent to which the German side was willing to engage in open communication with offshore colleagues. We would therefore argue that the Germans' inter-cultural communication efficacy had a direct impact on the accomplishment of a shared team identity and mutual trust (see arrow on the extreme left of Figure 1, which leads directly from efficacy to relational dimension).

If I want to collaborate with someone and like to have a phone conversation with him, then I will do it, on my own initiative. However, if I just do it because I have to, and the appointment is cancelled for some reason... then I don't make an effort to get a new appointment. (Respondent 4, Project leader)

\section{Outcome expectations}

As mentioned earlier, outcome expectations refer to the expected consequences of one's behaviour. If these outcomes are perceived as attractive, they motivate behaviour that is believed to lead to these outcomes (Ajzen and Fishbein, 1980; Bandura, 1997: 125). In our study, German respondents held the unanimous view that knowledge transfer was a prerequisite for achieving required performance outcomes. Performance problems were, conversely, consistently explained by the difficulties of transferring knowledge. For these reasons, the 
expectations of desired performance outcomes can be regarded as a prime motivator of knowledge transfer. In Figure 1, this is captured by the arrow that leads from outcome expectations to knowledge transfer willingness. However, respondents held mixed views on other outcomes of knowledge transfer, namely the resulting workload, task characteristics, and job security.

The workload created by knowledge transfer emerged as an important issue in all interviews. Many participants complained about the effort and time required to train Indian colleagues and answer all of their questions. While some believed that their workload would increase continuously with knowledge transfer, others argued that knowledge transfer would actually help alleviate their workload in the long run, by enabling Indian IT developers to complete tasks independently. This difference in beliefs seemed to be a function of both the length of the respondents' working relationship with India and of their varied points of reference. Some were concerned about the percentage increase in the absolute workload while others chose to focus on the ratio between the additional workload and workload saved through the transfer. In most cases, our respondents took part in knowledge transfer activities despite the extra effort it took, since they believed it was the only way to achieve any overall improvement over time. In a few cases, however, employees chose not to transfer important pieces of knowledge to the Indian side. It is therefore clear that the expected impact on their workloads affected employees' willingness to transfer knowledge (see Figure 1, arrow that leads from outcome expectations to knowledge transfer willingness):

Well, in the beginning, you were actually a bit frustrated and said 'Oh, it really gets on my nerves. I have easily spent three times longer on explanations than if I had done it myself. What does it give me, after all?' And then you really started to do sums: 'Well no, this task I will not give to India at all, it does not make sense. By the time I have explained it, by the time they have understood it - It won't work that way.' And then you did have team members here in Germany who said: ,No, I don't like it now, I don't like to transfer this, that won't work, that's too hard for me. (Respondent 30, Team leader)

More experienced respondents observed that they had learnt to distinguish between important and superfluous questions from the Indian side. They commented on failures of knowledge transfer within the Indian unit, which were causing Indian colleagues to address most questions directly to the German counterparts, instead of 
approaching their Indian colleagues in the same office. In order to force the Indian side to manage its knowledge better within the subsidiary unit, some German IT developers refused to respond to what they saw as 'unnecessary' questions. In some cases, such limitations in knowledge transfer created tensions between German and Indian colleagues, thus affecting the development of a positive shared team identity:

There is currently the demand from the responsible [Indian] department leader, with a long list of topics, and 'Here the Indian colleagues would like to be instructed, please'. ... I don't have the capacity for that. I also don't agree with it. This is currently a kind of topic of argument, where opinions clearly diverge. (Respondent 2, Group leader)

Outcome expectations regarding the workload could in this manner inhibit the development of the relational dimension of social capital, as indicated by the far left arrow in Figure 1 that leads directly from outcome expectations to the relational dimension of social capital. As mentioned before, some Germans also tried to avoid the workload of knowledge transfer by treating Indian colleagues as mere suppliers who had to deliver results, rather than view them as fellow team members. In this manner, a shared team identity, as part of the relational dimension of social capital, was not developed. In a few cases, German employees who were frustrated by the workload had even contributed actively to an Indian colleague's failure by not providing the necessary knowledge, in order to create an argument against the transfer of tasks to India.

Maybe you have noticed that he [the Indian colleague] hasn't really understood, but you do not tell him. Then he will take forever. You get no output, and in the end you do it yourself. That's the solution: 'I'll just do it myself then, even if I work overtime.' Then you will be able to say afterwards: 'This doesn't work, does it. (Respondent 5, Project section leader)

Respondents also reflected on outcomes of knowledge with regard to the tasks and the jobs of German IT developers. Some respondents, particularly those in the automotive safety department, were involved in the development of highly innovative products that created a vast amount of challenging new tasks for the German side. These respondents explained that the transfer of knowledge to India created the opportunity to move current, less challenging tasks offshore and focus on new, more attractive tasks: 
...we can concentrate on conceptual work, developing test concepts, plan tests, l'd like to call it test philosophy. There is the chance that you can offshore standard tasks or that you have more time for those tasks that go into more detail, require more experience." (Respondent 24, Group leader)

Given such innovative products, there were ample job opportunities in this department. These German employees therefore did not feel that supporting the task transfer by transferring knowledge would threaten jobs on the German side. By contrast, several respondents in the electronic control unit department were working on highly developed products that created fewer opportunities for new, innovative tasks. Consequently, Indian and German IT developers were competing for these desirable tasks. Transferring knowledge then meant enabling Indians to take on an increasing share of the attractive tasks, with the potential outcome of redundancies on the German side. Fears that the transfer would endanger one's own job were particularly strong when management had not communicated clear offshoring strategies and plans for German IT tasks in the future. Such outcome expectations reduced some Germans' willingness to transfer necessary knowledge (see Figure 1, arrow that leads from outcome expectations to knowledge transfer willingness).

I also see that colleagues here don't necessarily have the motivation to train Indian colleagues properly, which is also because ... if one suddenly says, in a running project where India was never planned for: 'Listen, from tomorrow there will also be two Indians', then there will first of all be disconcerted people in the German team. They will say: 'What's that for? Will my job be transferred to India? What are they actually doing?' (Respondent 9, Project section leader)

It is obvious that the competition for tasks, and the fear of offshoring one's own job, meant that German and Indian colleagues pursued partly different interests. This inhibited the development a shared team identity as part of the relational dimension of social capital (see arrow on the extreme left in Figure 1, leading directly from outcome expectations to the relational dimension of social capital). However, the degree to which negative outcome expectations regarding German jobs affected knowledge transfer behaviours depended also on how well social capital, in terms of personal relationships, was developed. After getting to know Indian colleagues in person, German IT developers were seen to put more effort into knowledge transfer, even when they feared for their jobs and anticipated more extensive knowledge transfer requirements in the future: 
[Interviewer: How motivated are German colleagues to try and communicate and transfer knowledge ...?] It works, if they know each other in person. That's incredibly motivating. Otherwise it is: 'The Indian has not clue about anything, but is supposed to do my work.' There is of course, everywhere, the overtone of the fear 'My job will go.' [Interviewer: And if they know each other?] Then it is easier, because then you can see that the colleague over there has trouble doing his work, he lacks something. And then you see yourself in him and ... simply picture him in a certain way, and the readiness to help is simply greater. (Respondent 24, Group leader)

\section{SELF-REINFORCING CIRCLES OF KNOWLEDGE TRANSFER: AN ANALYSIS}

From the above accounts, it is clear that social capital, efficacy, and outcome expectations were related to knowledge transfer ability or willingness, and that they were partly related to each other. The findings also demonstrate certain selfreinforcing circles of knowledge transfer. This observation is crucial, because it highlights the complexity of interrelationships between social capital and efficacy/outcome expectations, and the need to examine their influence simultaneously. An analysis of the three circles (outlined in Table 1 below) follows.

Insert Table 1 about here

\section{The Efficacy-Willingness-Effort-Success Circle (Circle 1)}

Both knowledge transfer efficacy and intercultural communication efficacy led to a circle, which was either virtuous or vicious. This is captured as Circle 1 in Figure 2 below, depicted by the arrows that link efficacy, willingness to transfer knowledge, knowledge transfer effort, knowledge transfer success, and efficacy. A snapshot view of this circle is depicted in Figure 3.

In our inquiry, intercultural communication efficacy reinforced actual communication with Indian colleagues and increased the opportunities to practice and improve intercultural communication. Likewise, the belief that effective knowledge transfer was possible increased the German side's willingness to transfer knowledge and to spend a lot of effort on it. Through this effort, knowledge on the Indian side had a better chance to improve to a satisfactory level: 
It was my personal commitment... Only because I reflected on how you can improve it ... only because of this I actually made it succeed. (Respondent 29, Team leader) In other words, this participant believed that his effort in knowledge transfer had led to knowledge transfer success (as indicated in Figure 2 by the arrow linking knowledge transfer effort and success). Experiencing such successes, in turn, reinforced efficacy beliefs on the German side, which completed the efficacy circle. Hence, German IT developers who had experienced successful knowledge transfer over time were seen to be more optimistic about knowledge transfer, even in the face of difficulties:

Someone who has already worked with India for a longer time will then say: Fine, it can work better. I have already experienced it better....Someone who has to work with India for the first time ... does not have a great tolerance for mistakes.

(Respondent 4, Project leader)

Conversely, when German employees did not put a lot of effort into knowledge transfer activities, this not only led to failed transfer initiatives, but such failures further reinforced the beliefs that knowledge transfer was not possible. This highlights the same circle, but in its negative form. Some German respondents cautioned that if they failed to provide sufficient support, Indian colleagues may be encouraged to move out of such projects, further affecting the performance of the IT offshoring relationship as a whole:

...if you show someone [the Indian colleague] how it works, what mistakes he is making, make clear to him what he is doing wrong, only then you can gain a profit from it. If we never show him, then he will never learn it and he also won't understand it and maybe feel treated unjustly and left out. ... Then he will move out of the project at the first given opportunity, because he can't stand it any longer, and then a new one comes in and the project will never get anywhere. (Respondent 19, Project member)

The experience of such failures entailed clearly negative efficacy beliefs:

In the end, this is the experience that those who have been doing it for a while take as point of reference, and they say 'Why should I do this at all?' (Respondent

\section{2, Project leader)}

Thus, the experience of failed knowledge transfer initiatives led to a belief that knowledge transfer was not likely to succeed and was therefore not worth it, which describes decreased knowledge transfer efficacy. Low knowledge transfer efficacy, 
in turn, reduced the effort put into transferring knowledge, which impeded the likelihood of knowledge transfer success, further reinforcing the negative efficacy beliefs. In this manner, the negative form of circle 1 was perpetuated.

Insert Figures 2 and 3 about here

\section{The Relational dimension-Willingness-Effort Circle (Circle 2)}

The second virtuous circle is represented by Circle 2 in Figure 2 above (arrows linking the relational dimension, willingness to transfer knowledge, knowledge transfer effort, and relational dimension). A snapshot view of this circle is depicted in Figure 4 below. With greater trust and shared team identities (relational dimension of social capital), the German side demonstrated a stronger willingness to share and transfer knowledge to their offshore counterparts, entailing a stronger knowledge transfer effort. We have described this before, when introducing the workings of the relational dimension of social capital. Importantly, this effort in transferring knowledge reinforced feelings of mutual trust and created a stronger identification with the international team. For example, a respondent noted that in his experience, taking the initiative to conduct extra training programmes for offshore colleagues created strong bonds in the onshore-offshore team:

Simply the fact that somebody from Germany comes over to India and is interested in the Indian colleagues and conducts extra training with them and is interested in their knowledge development, this of its own accord is great. The team building effort is included, so to say. (Respondent 29, Team leader)

The demonstration of knowledge transfer effort had thus led to a stronger team identity. On the other hand, when German colleagues restricted their effort in knowledge transfer, 'team spirit' suffered:

If the interaction between an Indian and a German colleague does not work well, this will affect the team. It happens that a communication problem develops between the Indian and the German colleague, for example when someone delays answers... And this has an effect on the team spirit. It does happen that ... a request is rejected

[by German colleagues] without an answer ... This does create certain tense relationships. (Respondent 16, Project member) 
This quote illustrates an occasion where a lack of effort in knowledge transfer diminished the sense of a shared team identity.

Insert Figure 4 about here

Our analyses imply that virtuous cycles are often hard to sustain. They are vulnerable to sudden changes in the offshore project teams, which can transform them into recursive vicious circles. For instance, increase in the offshore project teams' attrition rates can significantly weaken the relational dimension of social capital, as well as efficacy, which in turn has a detrimental effect on knowledge transfer willingness and effort, further weakening the bonds of trust and identity. Similarly, when fears about job losses and workloads mount, (say) in response to senior managers' announcements about moving more work offshore, it can again harm the development of the relational dimension of social capital, triggering the vicious version of circle 2 again.

\section{The Cognitive dimension-Ability-Success Circle (Circle 3)}

Clearly, a shared contextual understanding between onshore and offshore team members (cognitive dimension of social capital) improved the ability of onshore colleagues to transfer complex and tacit forms of knowledge, thereby having a positive impact on successful transfer. We have described these links before, in the section on the cognitive dimension of social capital. These knowledge transfer successes, in turn, reinforced the shared contextual understanding. In this manner, a virtuous circle was set in motion, illustrated by the circle 3 in Figure 2 (arrows that link cognitive dimension, ability to transfer knowledge, knowledge transfer success, and cognitive dimension), a snapshot view of which is depicted in Figure 5 below. Respondents' accounts provided noteworthy illustrations of this circle in practice. For example, offshore colleagues' greater exposure to the mechanics of cars at the customer's site had in some cases helped develop a better shared understanding of the automotive system, which facilitated the transfer of complex system knowledge: 
We now have some Indian system developers in the project who have also been to the US, and have also worked in the vehicle with the customer. ... They are now also able to take care of more complex tasks. (Respondent 12, Project leader)

The Indian colleagues' technical understanding had thus converged towards that of their German counterparts. However, to sustain such a shared understanding, managing turnover in the offshore unit was crucial:

The key to success is that you work with the same people over years. .. You need some constants in order to be able to communicate at the same level and not have to explain everything ten times. (Respondent 8, Team leader)

Conversely, when knowledge transfer initiatives ended in failures, for example due to employee attrition, shared contextual understanding was not improved:

We do knowledge transfer continuously, and [with high attrition levels] knowledge that is transferred is often not preserved in the Indian subsidiary. Not to talk of developing the knowledge level any further, we would even be happy if it just stayed there and we would not have to do it again every time new people arrive.

(Respondent 10, Group leader)

Hence, when knowledge transfer was not successful, for example due to employee attrition, a shared contextual understanding could not develop. But such an understanding was crucial for the German side's ability to transfer knowledge. In this manner, a vicious circle of knowledge transfer failures, linked to the inability of onshore -offshore employees to arrive at a cognitive common ground, could develop.

Insert Figure 5 about here

\section{DISCUSSION}

The three circles in our model provide several insights into social capital, efficacy and outcome expectations, the extent to which these factors are shaped by the IT offshoring settings, and their inter-relationships during the evolution of the knowledge transfer process between onshore and offshore IT units. As evident in our discussion above, these factors clearly impact on knowledge transfer success (see Figure 2), which then feeds into efficacy (Circle 1) and into the cognitive dimension of social capital (Circle 3). For example, the structural and relational dimensions of social capital impacted on the knowledge transfer abilities of onshore IT developers, 
thereby influencing the success of knowledge transfer activities, which again had a substantive effect on the development of a shared contextual understanding. The creation and development of social capital influences efficacy indirectly, through the shared team identity-willingness-effort-success-efficacy link (Circles 2 and 1). As the IT offshoring relationship evolves further, efficacy beliefs and outcome expectations of the onshore IT teams influence both the relational and cognitive dimensions, albeit indirectly, through the efficacy/outcome expectations-willingness-effort-trust chain (see Figure 2). As we noted earlier, these influences and inter-relationships are quite dynamic in nature. They can have both positive and negative consequences, which makes management of complex IT offshoring engagements very difficult for managers.

Amongst all the IT offshoring context-related factors, employee turnover on the Indian side appeared to be the hardest to manage. This turnover of IT developers had an effect on the extent to which a shared understanding (the cognitive dimension) could develop over time. Such a shared understanding was clearly a precondition for improvements in the knowledge transfer abilities of onshore IT teams. The turnover levels on the offshore side made it harder to develop trust and team identity over time, and affected German teams' efficacy beliefs and outcome expectations regarding their workload, and hence their willingness and effort put into transferring knowledge. While acknowledging that it may be impossible to achieve turnover levels in the offshore IT teams that are comparable to those in onshore teams, respondents argued that these levels have to be kept at least at manageable levels, for otherwise the three virtuous circles may not be generated or maintained.

Finally, knowledge transfer efficacy and outcome expectations regarding workloads were affected by the geographical distance and other contextual considerations, especially when tacit knowledge had to be transferred as part of the collaborative IT development. Those German respondents who did not believe that successful knowledge transfer was possible justified this mainly by citing the lack of informal interactions, shared understanding, high turnover, etc. The international context of the IT offshoring relationship also came into play when differences in language and communication styles created low intercultural communication efficacy. Likewise, outcome expectations in some cases were linked to the 
competition between onshore and offshore IT groups for interesting tasks and to the fears of job losses in Germany.

\section{Theoretical contributions}

From a theoretical perspective, this study shows how social capital is particularly important, and, at the same time, especially difficult to achieve in an IT offshoring setting. The study advances extant IS research on knowledge transfer in IT offshoring relationships by combining insights from the social capital, efficacy and outcome expectations literature. We demonstrated why these dimensions are crucial in the IT offshoring context, whilst also noting that they may apply to a wider context. In this paper, we have argued for and built on a clear conceptual distinction between knowledge transfer ability and willingness. Whilst the division between knowledge transfer ability and willingness has been introduced more than a decade ago (see Hansen, 1999; Inkpen \& Tsang, 2005), it is not often made in IS research on knowledge sharing or transfer. This distinction helps build a more nuanced view of IT offshoring knowledge transfer processes than what is offered in previous IS research. The social capital, efficacy, outcome expectations, and knowledge transfer model (Figure 2 above) provides an in-depth explanation of knowledge transfer mechanisms in IT offshoring relationships, by highlighting a) the linear relationships between social capital, efficacy/outcome expectations and knowledge transfer ability and willingness and b) the workings of the self-reinforcing circles. Further, this study not only emphasizes the influence of distinctive factors on ability and willingness to transfer knowledge, but also elaborates on the complex interrelations between the factors (i.e. social capital, efficacy, and outcome expectations) themselves.

With regard to individual and linear influences, the conceptual separation of ability and motivation allowed us to identify the impacts of the three dimensions of social capital on either ability or willingness of knowledge transfer, or both. It also shows how efficacy and outcome expectations generate motivational mechanisms of knowledge transfer because they crucially affect the willingness (although they don't influence the ability) of onshore IT developers to transfer knowledge. Empirical IS studies, such as those reviewed in our paper, tend to simply examine actual knowledge transfer, a measure that taps only on the outcomes of the psychological mechanisms involved in knowledge transfer, and not on the psychological mechanisms per se. Even the few studies in the broader management literature that 
do distinguish between ability and motivation (e.g. Chang et al, 2012; Reagans \& McEvily, 2003; Minbaeva, 2012) either ignore the mechanisms linked to efficacy and outcome expectations, or only mention their effects in passing. Our study suggests that efficacy and social capital perpetuate themselves through self-reinforcing circles, as long as the external contextual factors (e.g. turnover of IT developers in the offshore unit) do not change dramatically. These circular mechanisms generate an even stronger, longer lasting influence on knowledge transfer, which highlights the need to take all of these mechanisms into account when studying knowledge transfer in IT offshoring research.

The IT offshoring knowledge transfer model developed above support some of the early literature on social capital, efficacy and outcome expectations. For instance, the circle regarding efficacy (circle 1 in Figure 2) echoes research on selfreinforcing circles of efficacy and performance (Bandura \& Wood, 1989; Lindsley et al., 1995). Similarly the two circles created by social capital (circle 2 and circle 3), accord with Nahapiet and Ghoshal's (1998) model of social capital and the creation of intellectual capital, in which they argue for a feedback relationship between 'new intellectual capital created...' and the three dimensions of social capital (1998: 251). Referring to the literature on self-reproducing social practices (Brown \& Duguid, 1991; Giddens, 1984), Nahapiet and Ghoshal posit that social and intellectual capital co-evolve in mutually dependent and interactive ways (1998: 259-260). In their research, Nahapiet and Ghoshal assume that emerging shared knowledge shapes only the three dimensions of social capital. So far, this has been the commonly accepted conceptualization even in IS research on knowledge transfer. Our model presents a more differentiated theoretical view, by adding the related factors of efficacy and outcome expectations, and by distinguishing between knowledge transfer ability and willingness.

The interrelations we found between social capital, efficacy, and outcome expectations suggest that IS research must take a synoptic view of these three factors and the mechanisms they generate, unlike prior approaches that tend to focus only on social capital. Our analysis indicates that trust and a sense of shared team identity between onshore and offshore IT development teams is a function of efficacy beliefs and outcome expectations, such as fears of losing interesting tasks or jobs (see the arrows linking outcome expectations and efficacy with the relational dimension of social capital in Figure 2). Further, we demonstrated how through their 
impact on knowledge transfer success, efficacy, outcome expectations and the relational and cognitive dimension of social capital all feed into the three selfperpetuating circles, creating even closer interlinkages between themselves. As mentioned earlier, this suggests that IS research on knowledge transfer needs to explore mechanisms of social capital in concert with efficacy and outcome expectations.

\section{CONCLUSION}

In this paper, we have argued that knowledge transfer mechanisms in IT offshoring relationships can be understood better by considering social capital in concert with knowledge senders' efficacy and outcome expectations. Clearly, this study may have significance for many other organisational contexts as well. Given that social capital is an important antecedent of employees' ability and willingness to transfer knowledge (see Hansen, 1999; Inkpen \& Tsang, 2005; Nahapiet \& Ghoshal, 1998; Wasko et al., 2005) and the longstanding view that efficacy-outcome expectations are generic, motivational principles, the mechanisms emphasised here are likely to be relevant for knowledge transfer behaviours in general. However, further research is needed to consolidate this claim, and to explore the contents of efficacy beliefs and outcome expectations in other knowledge transfer situations.

\section{Implications for practitioners}

The findings of our study indicate that managers should pay attention not only to IT groups' ability to transfer knowledge to an offshore destination, but also to their willingness to do so. In the participating firm, several practices were in place to support knowledge transfer ability, for example technology tools, coordination meetings and periodic mutual visits. However, the German IT developers' varying motivation to transfer knowledge was not always addressed. Most importantly, some managers did not provide sufficiently clear and explicit perspectives and plans for the future of their German colleagues' tasks and careers. Clear and well communicated strategies of this sort are however necessary in order to avoid insecurity and fears of negative knowledge transfer outcomes.

Our findings also highlight how knowledge transfer success is often a consequence of IT developers' own effort, which then leads to virtuous circles of efficacy and social capital. This insight should encourage employees who are tasked 
with knowledge transfer to be more optimistic about its potential success and thus develop better knowledge transfer efficacy, which as our study suggests contributes to knowledge transfer success. For this message to work, however, a greater interaction between onshore departments with more experience of IT offshoring and those with less experience is crucial. Such exchanges can help provide examples of successes and best practices, and encourage more positive expectations and efficacy in the face of initial difficulties.

The senior management on the onshore side would also be well advised to finance more visits of onshore IT teams to the offshore unit. As we saw in our empirical data, it was clearly difficult for German colleagues to apprehend the information needs on the Indian side. These problems were manifest, for example, in the inadequate software specifications produced by the German side. However, several respondents reported that a visit to the Indian site had made them more aware of the need to provide more detailed background information in their specification documents. During such visits they also found that Indian colleagues were very friendly and highly committed to their work. Visits to India had therefore inspired them to work harder in supporting their Indian colleagues. We would suggest that such visits and face-to-face contact time can go a long way in enhancing inter-cultural competence, eliminating cultural stereotyping and improving the effectiveness of international team-working.

Our study suggests several constraints to knowledge transfer in an IT offshoring setting. Prominent among these are employee turnover and a lack of detailed and deep knowledge about the end product (e.g. Automobiles) in the offshore unit. It is unlikely that difficulties like these be completely surmounted soon. It is unrealistic, for instance, to hope that employee tenure of ten years or more, as common on the German site, becomes the norm in the Indian context. However, several measures can be taken to achieve at least an average tenure of three to four years in an offshore IT team. Transferring challenging tasks to the Indian subsidiary can create novel opportunities for offshore team members. Such opportunities can encourage them to stay with a project for a longer period. At the same time, increasing their responsibilities is likely to enhance the Indian colleagues' experience and expertise and, through this, the cognitive dimension of social capital. To accommodate for the Indian employees' desire to experience new IT tasks regularly, a controlled programme of job rotation within the subsidiary could motivate Indian 
colleagues to stay with the firm, and at the same time broaden their knowledge base. Such job rotations would require systematic plans for transition and knowledge sharing within the Indian subsidiary. Also, in this specific case, offshore IT developers' understanding and knowledge about automobiles could be improved by incrementally transferring the responsibility for developing products for the Indian automotive industry to the subsidiary unit.

\section{Limitations and future research}

Our study provides an in-depth, qualitative perspective of the mechanisms by which social capital, efficacy, and outcome expectations influenced knowledge transfer ability and willingness in a single IT offshoring relationship. We acknowledge that these concepts are, however, grounded in a long tradition of quantitative research, using measurement through Likert scales (see Bandura, 1997, for a review on efficacy and outcome expectations) and network analysis (see Hansen, 1999; Tsai \& Ghoshal, 1998, for research on social ties and social capital). Although we have developed a tentative model of knowledge transfer based on our qualitative analysis, for further triangulation, it may be necessary to use well-established quantitative measures to test our model in a range of IT offshoring settings. In addition, more detailed insights into the development of the three circles over time could be gained through additional qualitative methods, in particular, through ethnographic research of collaborative IT development, or diary studies that capture the thoughts and feelings of respondents at regular intervals and after critical incidents.

We agree that qualitative studies should set the ground for transferability rather than focusing on generalisability (Lincoln \& Guba, 2002). In this paper, we have documented the embedded features of knowledge transfer in one IT offshoring relationship, thereby allowing other researchers to investigate its transferability to other, analogous contexts. In our view, it would be particularly useful to explore whether similar mechanisms of knowledge transfer can be found in other national contexts and other industries. For example, different combinations of offshore and onshore countries may create different challenges that affect the development of social capital. This would be especially relevant for the choice between IT offshoring and IT near-shoring (i.e., IT outsourcing to countries that enjoy geographical and cultural proximity). Compared to the IT industry, others (e.g., manufacturing) may 
rely to a much smaller extent on tacit knowledge. This may lead to smoother processes of knowledge transfer and more positive efficacy beliefs and outcome expectations although we would argue that the principles of social capital, efficacy, and outcome expectations are still likely to be important in these other contexts.

Despite its ability to explain the evolution of knowledge transfer processes through a non-linear model, we recognise that our model does have some linear relationships. These reflect our respondents' world views accurately, but we agree that any linear relationship almost always simplifies the workings of complex social and psychological variables. In this sense, we may point out that our model too is a particular schemata generated from our respondents' version of social reality. As argued by configuration theory (e.g., Meyer et al., 1993; Zimmermann, 2011), social processes (like knowledge transfer in IT offshoring arrangements) tend to consist of complex constellations of mutual influences rather than unidirectional dependencies. It is also important to point out that we drew only on interviews with onshore IT groups. Clearly, to appreciate the socio-psychological mechanisms of onshore to offshore knowledge transfer more fully, we would also need to take into account the experiences of IT development teams in offshore units (see Ravishankar et al., 2010; Williams, 2010). Finally, we did not explore any of the characteristics of German national culture and how they may have affected some of the positions taken by the respondents in their interactions with the offshore unit. From a cultural standpoint, it may be an interesting exercise to examine in depth how onshore IT developers from other nationalities (e.g., American or British) interact with the subsidiary unit during knowledge transfer processes, and compare them with our study.

\section{REFERENCES}

Ajzen, I. \& Fishbein, M. (1980) Understanding Attitudes and Predicting Social Behavior. Prentice-Hall, Englewoods-Cliffs, NJ.

Argote, L. \& Ingram, P. (2000) Knowledge transfer: A basis for competitive advantage in firms. Organizational Behavior and Human Decision Processes, 82, 150-169.

Bandura, A. (1997) Self-efficacy: The Exercise of Control. W.H. Freeman, New York. Bandura, A. and Wood, R. (1989) Effect of perceived controllability and performance standards on self-regulation of complex decision making. Journal of Personality and Social Psychology, 56, 805-814. 
Bhagat, R.S., Kedia, B.L., Harveston, P.D. \& Triandis, H.C. (2002) Cultural variations in the cross-border transfer of organizational knowledge: an integrative framework. Academy of Management Review, 27, 204-221.

Bock, G.W., Zmund, R.W. \& Kim, Y.G. (2005) Behavioral intention formation in knowledge sharing: examining the roles of extrinsic motivators, social-psychological forces, and organizational climate. MIS Quarterly, 29, 87-111.

Brown, J.S. \& Duguid, P. (1991) Organizational learning and communities-ofpractice: toward a unified view of working, learning and innovation. Organization Science, 2, 40-57.

Chang, Y.-Y., Gong, Y. \& Peng, M.W. (2012) Expatriate knowledge transfer, subsidiary absorptive capacity, and subsidiary performance. Academy of Management Journal, 55, 927-948.

Chen, Ch.-J. \& Hung, Sh.-W. (2010) To give or to receive? Factors influencing members' knowledge sharing and community promotion in professional virtual communities. Information and Management, 47, 226-236.

Chiu, Ch.-M., Hsu, M.H. \& Wang, E.T.G. (2006) Understanding knowledge sharing in virtual communities: an integration of social capital and social cognitive theories. Decision Support Systems, 42, 1872-1888.

Chua, A.L. \& Pan, S.L. (2008) Knowledge transfer and organizational learning in IS offshore sourcing. Omega, 36, 267-281

Cohen, L. \& El-Sawad, A. (2007) Lived experiences of offshoring: An examination of UK and Indian financial service employees' accounts of themselves and one another. Human Relations, 60, 1235-1262.

Cummings, J.N. (2011) Geography is alive and well in virtual teams. Communications of the ACM, 54, 24-26.

Dibbern, J., Winkler, J. and Heinzl, A. (2008) Explaining variations in client extra costs between software projects offshored to India. MIS Quarterly, 32, 333-366.

Eden, L. (2009) Letter from the editor-in-chief: reverse knowledge transfers, culture clashes and going international. Journal of International Business Studies, 40, 177180

Eisenhardt, K.M. (1989) Building theories from case study research. Academy of Management Review, 14, 532-550.

Giddens, A. (1984) The Constitution of Society: Outline Theory of Structuration. Polity Press, Cambridge, UK. 
Gregory, R. (2010) Review of the IS offshoring literature: the role of cross-cultural differences and management practices, Proceedings of the 18th European Conference on Information Systems, Pretoria, South Africa.

Gupta, A.K. \& Govindarajan, A. (2000) Knowledge flows within multinational cooperations. Strategic Management Journal, 21, 473-496.

Hansen, M.T. (1999) The search-transfer problem: the role of weak ties in sharing knowledge across organization subunits. Administrative Science Quarterly, 44, 82111.

Herbsleb, J.D. \& Grinter, R.E. (1999) Splitting the organization and integrating the code: Conway's law revisited. Proceedings of the International Conference on Software Engineering, Los Angeles, CA.

Herbsleb, J.D. \& Moitra, D. (2001) Global Software Development. IEEE Software, 16-20.

Hsu, M.-J., Ju, T.L., Yen, Ch.-H. \& Chang, Ch.-M. (2007) Knowledge sharing behaviour in virtual communities: the relationship between trust, self-efficacy, and outcome expectations. International Journal of Human-Computer Studies, 65, 153169.

Inkpen, A.C. \& Tsang, E.W.K. (2005) Social capital, networks, and knowledge transfer. Academy of Management Review, 30, 146-165.

Kang, M., Kim, Y.-G. \& Bock, G.-W. (2010) Identifying different antecedents for closed vs. open knowledge transfer. Journal of Information Science, 36, 585-602.

Kankanhalli, A., Tan, B.C.Y. \& Wei, K.-K. (2005) Contributing knowledge to electronic knowledge repositories: an empirical investigation. MIS Quarterly, 29, 113143.

Kuo, F.-Y. \& Young, M.-L. (2008) A study of the intention-action gap in knowledge sharing practices. Journal of the American Society for Information Science and Technology, 59, 1224-1237.

Leonardi, P.M. \& Bailey, D.E. (2008) Transformational technologies and the creation of new work practices: making implicit knowledge explicit in task-based offshoring. MIS Quarterly, 32, 411-436.

Levina, N. \& Vaast, E. (2008) Innovating or doing as told? Status differences and overlapping boundaries in offshore collaboration. MIS Quarterly, 32, 307-332.

Lin, H.-F. (2007) Effects of extrinsic and intrinsic motivation on employee knowledge sharing intentions. Journal of Information Science, 33, 135-149. 
Lin, T.-Ch. \& Huang, Ch.-Ch. (2010) Withholding effort in knowledge contribution: The role of social exchange and social cognitive on project teams. Information and Management, 47, 188-196.

Lincoln, Y.S. \& Guba, E.G. (2002) Judging the quality of qualitative case study research. In: The Qualitative Researcher's Companion, Huberman, A.M. \& Miles, M.B. (eds), pp. 205-216. Sage, London, UK.

Lindsley, D.H., Brass, D.J. \& Thomas, J.B. (1995) Efficacy-performance spirals: A multilevel perspective. Academy of Management Review, 20, 645-678.

Meyer, A.D., Tsui, A.S. \& Hinings, C.R. (1993) Configurational approaches to organizational analysis. Academy of Management Journal, 36, 1175-1195.

Metiu, A. (2006) Owning the code: Status closure in distributed groups. Organization Science, 17, 418-435.

Minbaeva, D.B. \& Michailova, S. (2004) Knowledge transfer and expatriation in multinational corporations. Employee Relations, 26, 663-679.

Nahapiet, J. \& Ghoshal, S. (1998) Social capital, intellectual capital and the organizational advantage. Academy of Management Review, 23, 242-266.

Newell, S. \& Swan, J. 2000. Trust and inter-organizational Networking. Human Relations, 53, 287-328

Nonaka, I. (1994) Dynamic theory of organizational knowledge creation. Organization Science, 5, 14-37.

Oshri, I., van Fenema, P. \& Kotlarski, J. (2008) Knowledge transfer in globally distributed teams: the role of transactive memory. Information Systems Journal, 18, 593-616.

Ravishankar, M.N., Cohen, L. \& El-Sawad, A. (2010) Strategies of resistance, accommodation and the pursuit of aspiration among new economy firms in India: reflections from two cases. Industrial Relations Journal, 41, 154-167.

Ravishankar, M.N., Pan, S.L. \& Myers, M.D. (2013) Information technology offshoring in India: a postcolonial perspective. European Journal of Information Systems, 22, doi:10.1057/ejis.2012.32, 1-16.

Reagans \& McEvily (2003) Network structure and knowledge transfer: the effects of cohesion and range. Administrative Science Quarterly, 48, 240-267.

Rottman, J.W. (2008) Successful knowledge transfer within offshore supplier networks: a case study exploring social capital in strategic alliances. Journal of Information Technology, 23, 31-43. 
Szulanski, G. (1996) Exploring internal stickiness: impediments to the transfer of best practice within the firm. Strategic Management Journal, 17, 27-43.

Tsai, W. \& Ghoshal, S. (1998) Social capital and value creation: the role of intrafirm networks. Academy of Management Journal, 41, 464-476.

Van Wijk, R., Jansen, J.J.P. \& Lyles, M.A. (2008) Inter- and intra-organizational knowledge transfer: a meta-analytic review and assessment of its antecedents and consequences. Journal of Management Studies, 45, 830-853.

Vlaar, P.W.L., Fenema, P.C. \& Tiwari, V. (2008) Cocreating understanding and value in distributed work: how members of onsite and offshore vendor teams give, demand, and break sense. MIS Quarterly, 32, 227-255.

Wasko, M. \& Faraj, S. (2005) Why should I share? Examining social capital and knowledge contribution in electronic networks of practice. MIS Quarterly, 29, 35-57.

Williams, C. (2011) Client-vendor knowledge transfer in IS offshore outsourcing: insights from a survey of Indian software engineers. Information Systems Journal, 21, 335-356.

Winkler, J., Dibbern, J. \& Heinzl, A. (2008) The impact of cultural differences in offshore outsourcing. Case study results from German-Indian application development projects. Information Systems Frontiers, 10, 243-258.

Yin, R.K. (2009) Case Study Research: Design and Methods, $4^{\text {th }}$ edn. Sage, London, UK.

Zimmermann, A. (2011) Interpersonal relationships in transnational, virtual teams towards a configurational perspective. International Journal of Management Reviews, 13, 59-78.

Zimmermann, A. \& Ravishankar, M.N. (2011) Collaborative IT offshoring relationships and professional role identities: reflections from a field study. Journal of Vocational Behavior, 78, 351-360.

Insert Appendix here 


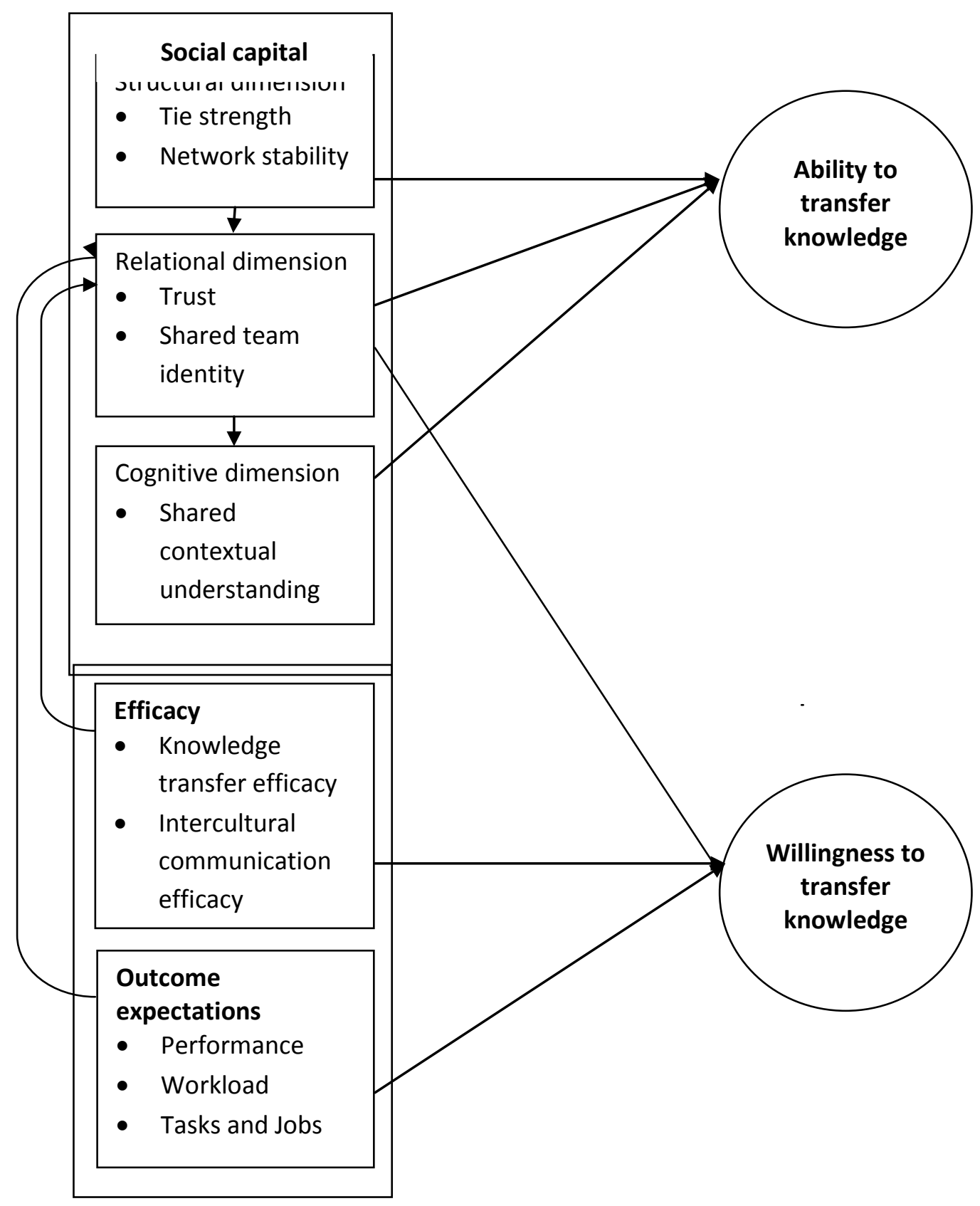

Figure 1. Social capital, efficacy, outcome expectations, and knowledge transfer 


\begin{tabular}{|c|c|}
\hline Circle No. & Name \\
\hline 1 & The Efficacy-Willingness-Effort-Success Circle \\
\hline 2 & The Relational dimension-Willingness-Effort Circle \\
\hline 3 & The Cognitive dimension-Ability-Success Circle \\
\hline
\end{tabular}

Table 1. An outline of the self-reinforcing circles 


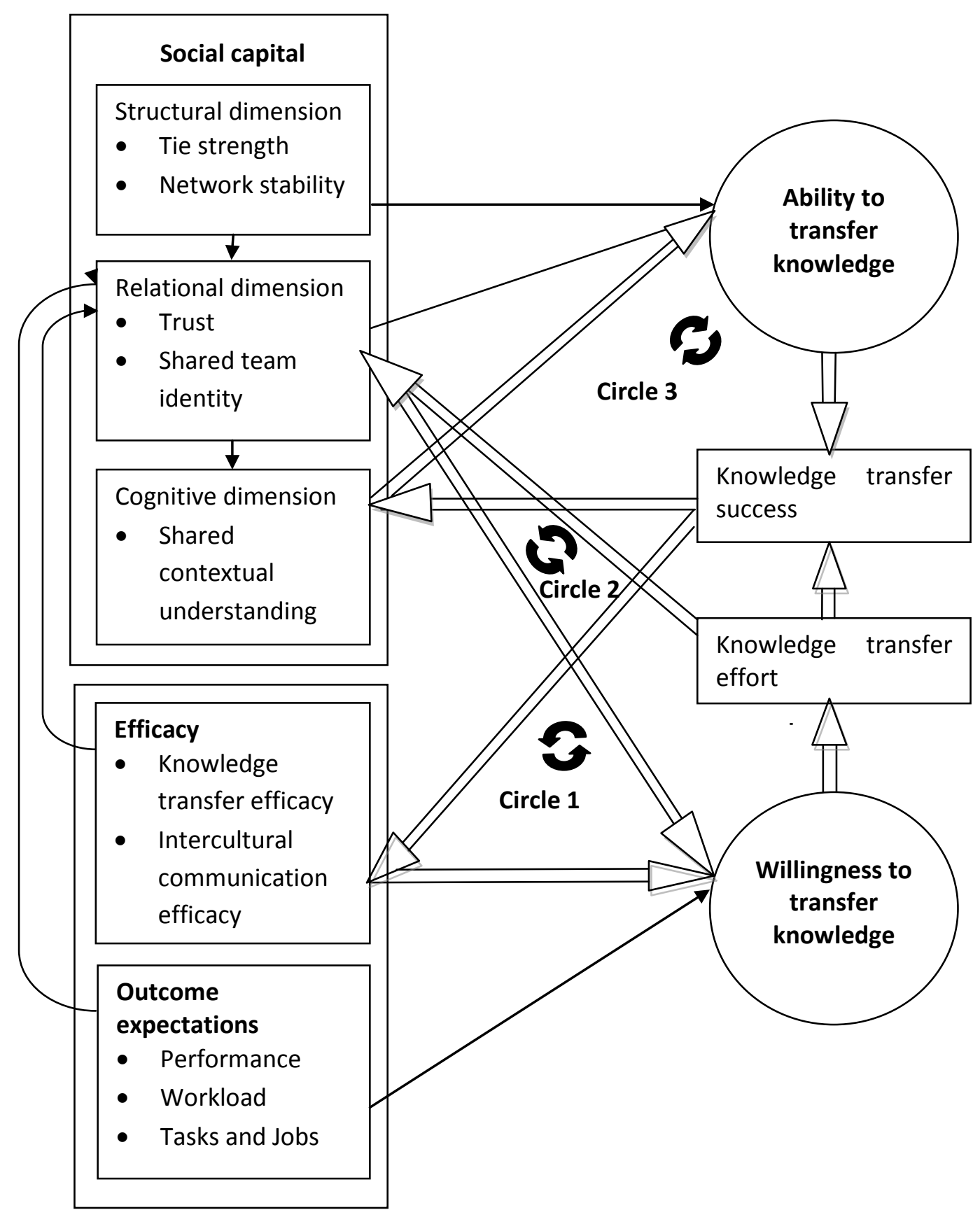

Figure 2. Extended model: Self-reinforcing circles 

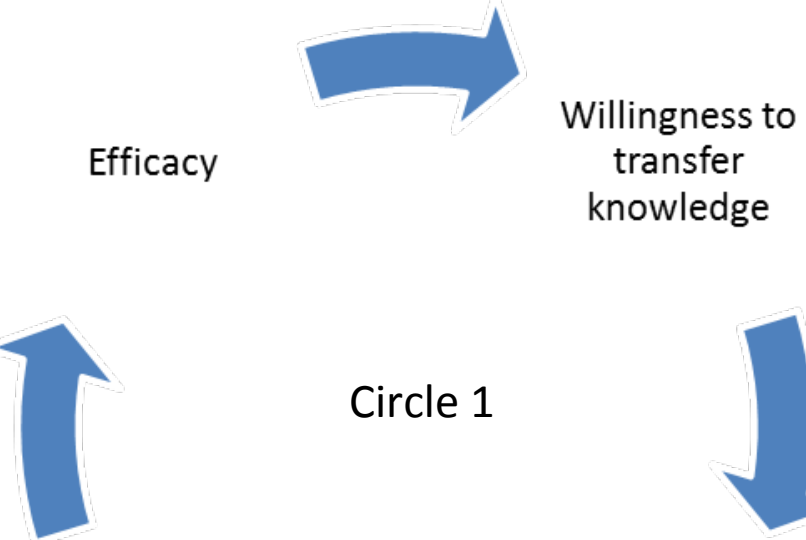

Circle 1

Knowledge transfer success

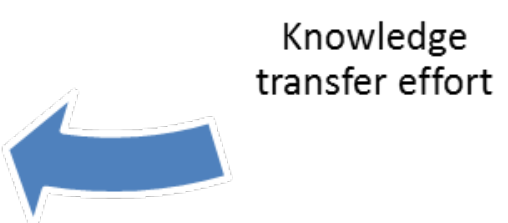

Figure 3. The Efficacy-Willingness-Effort-Success Circle 


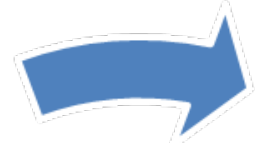

$$
\begin{aligned}
& \text { Relational } \\
& \text { dimension }
\end{aligned}
$$
Willingness to transfer
knowledge

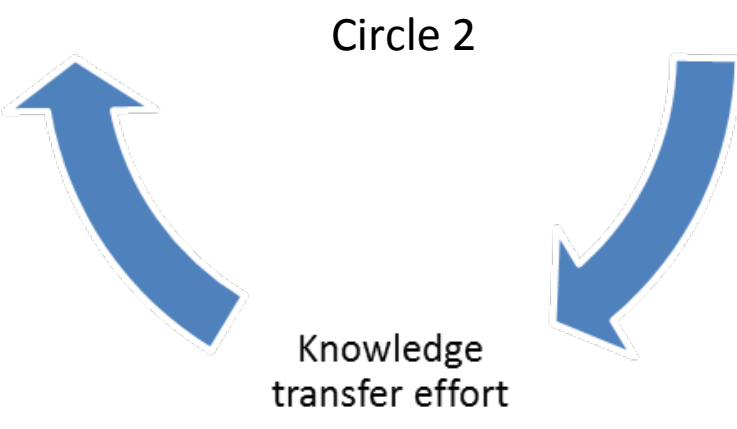

Figure 4. The Relational dimension-Willingness-Effort Circle 


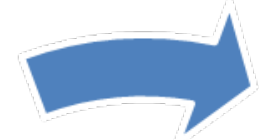
Cognitive
dimension
Ability to transfer knowledge

Circle 3

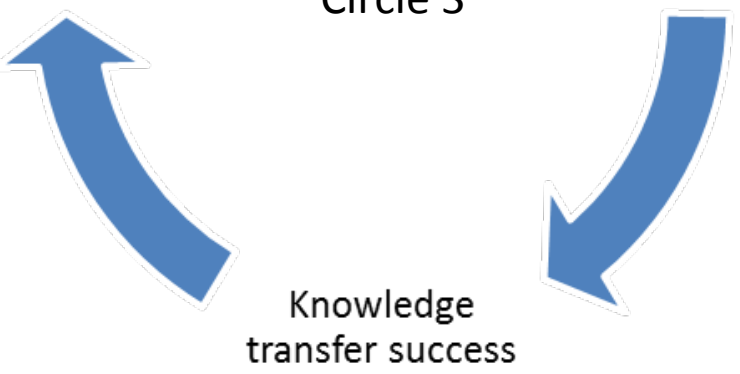

Figure 5. The Cognitive dimension-Ability-Success Circle 
APPENDIX A. Interview respondents

\begin{tabular}{|c|c|c|}
\hline \multicolumn{3}{|c|}{ Electronic Control Units department } \\
\hline Departmental group & $\begin{array}{l}\text { Participant } \\
\text { numberl title }\end{array}$ & $\begin{array}{l}\text { Role in collaboration with } \\
\text { India }\end{array}$ \\
\hline $\begin{array}{l}\text { Management } \\
\text { advisory group }\end{array}$ & $\begin{array}{l}\text { 1) 'Global } \\
\text { Coordination' }\end{array}$ & $\begin{array}{l}\text { Department level coordinator } \\
\text { for global collaboration, } \\
\text { including India }\end{array}$ \\
\hline \multirow[t]{4}{*}{$\begin{array}{l}\text { Software function } \\
\text { development group }\end{array}$} & 2) Group leader & $\begin{array}{l}\text { Offshoring strategy and } \\
\text { capacity planning within the } \\
\text { group }\end{array}$ \\
\hline & 3) Team leader & $\begin{array}{l}\text { Group level coordinator for } \\
\text { collaboration with India }\end{array}$ \\
\hline & 4) Project leader & Collaboration within project \\
\hline & $\begin{array}{l}\text { 5) Project section } \\
\text { leader }\end{array}$ & $\begin{array}{l}\text { Group level coordinator for } \\
\text { collaboration with India }\end{array}$ \\
\hline \multirow{4}{*}{$\begin{array}{l}\text { Customer-specific } \\
\text { software } \\
\text { development } \\
\text { (customer 1) }\end{array}$} & 6) Team leader & Collaboration within team \\
\hline & 7) Team leader & $\begin{array}{l}\text { Group level coordinator for } \\
\text { collaboration with India }\end{array}$ \\
\hline & 8) Team leader & Collaboration within team \\
\hline & $\begin{array}{l}\text { 9) Project section } \\
\text { leader }\end{array}$ & Collaboration within project \\
\hline \multirow[t]{3}{*}{$\begin{array}{l}\text { Customer-specific } \\
\text { software } \\
\text { development } \\
\text { (customer 2) }\end{array}$} & 10) Group leader & $\begin{array}{l}\text { Offshoring strategy and } \\
\text { capacity planning within the } \\
\text { group; Group and area level } \\
\text { coordinator for collaboration } \\
\text { with India }\end{array}$ \\
\hline & 11) Project leader & Collaboration within project \\
\hline & 12) Project leader & $\begin{array}{l}\text { Collaboration within project; } \\
\text { Previously Group level } \\
\text { coordinator for collaboration }\end{array}$ \\
\hline
\end{tabular}




\begin{tabular}{|c|c|c|}
\hline & & with India \\
\hline & 13) Project member & $\begin{array}{l}\text { Group level coordinator for } \\
\text { collaboration with India }\end{array}$ \\
\hline & $\begin{array}{l}\text { 14) Project section } \\
\text { leader }\end{array}$ & Collaboration within project \\
\hline & 15) Project member & Collaboration within project \\
\hline & 16) Project member & Collaboration within project \\
\hline $\begin{array}{l}\text { Customer-specific } \\
\text { software } \\
\text { development } \\
\text { (customer 3) }\end{array}$ & $\begin{array}{l}\text { 17) Project section } \\
\text { leader }\end{array}$ & Collaboration within project \\
\hline $\begin{array}{l}\text { Customer support for } \\
\text { motor control }\end{array}$ & 18) Project member & Collaboration within team \\
\hline $\begin{array}{l}\text { Interface group } \\
\text { between ECU } \\
\text { development and } \\
\text { manufacturing sites }\end{array}$ & 19) Team leader & Collaboration within team \\
\hline $\begin{array}{l}\text { Software tool } \\
\text { development for } \\
\text { heavy motor vehicles }\end{array}$ & 20) Group leader & $\begin{array}{l}\text { Offshoring strategy and } \\
\text { capacity planning within the } \\
\text { group; Collaboration within } \\
\text { group }\end{array}$ \\
\hline $\begin{array}{l}\text { Software tool } \\
\text { development for } \\
\text { various internal } \\
\text { departments }\end{array}$ & 21) Team leader & Collaboration within team \\
\hline $\begin{array}{l}\text { Software tool } \\
\text { development for } \\
\text { various internal } \\
\text { departments }\end{array}$ & 22) Project member & $\begin{array}{l}\text { Collaboration within project as } \\
\text { expatriate employee in India }\end{array}$ \\
\hline \multicolumn{3}{|c|}{ Automotive Safety Systems department } \\
\hline Departmental group & $\begin{array}{l}\text { Participant } \\
\text { numberl title }\end{array}$ & $\begin{array}{l}\text { Role in collaboration with } \\
\text { India }\end{array}$ \\
\hline
\end{tabular}




\begin{tabular}{|c|c|c|}
\hline $\begin{array}{l}\text { Management } \\
\text { advisory group }\end{array}$ & $\begin{array}{l}\text { 23) India } \\
\text { coordinator }\end{array}$ & $\begin{array}{l}\text { Department level coordinator } \\
\text { for global collaboration, } \\
\text { including India }\end{array}$ \\
\hline \multirow[t]{3}{*}{ Software testing } & 24) Group leader & $\begin{array}{l}\text { Offshoring strategy and } \\
\text { capacity planning within the } \\
\text { group }\end{array}$ \\
\hline & 25) Team leader & Collaboration within team \\
\hline & 26) Team member & $\begin{array}{l}\text { Group level coordinator for } \\
\text { collaboration with India, also } \\
\text { responsible developing future } \\
\text { strategies of organising } \\
\text { onshore and offshore resources }\end{array}$ \\
\hline Hardware testing & 27) Group leader & $\begin{array}{l}\text { Offshoring strategy and } \\
\text { capacity planning within the } \\
\text { group }\end{array}$ \\
\hline \multirow{3}{*}{$\begin{array}{l}\text { Customer-specific } \\
\text { software } \\
\text { development }\end{array}$} & 28) Team leader & Collaboration within team \\
\hline & 29) Team leader & Collaboration within team \\
\hline & 30) Team leader & Collaboration within team \\
\hline
\end{tabular}

\section{APPENDIX B. Key NVivo nodes ${ }^{1}$}

Knowledge transfer

- Knowledge creation and innovation

- Communicating

- Avoiding vs. supporting transfer of tasks to India

- Willingness and effort

Structural dimension of social capital

- Virtuality, visits

- Turnover levels Indian employees

- Coordination mechanisms

o Window people versus broad contact

o Coordination meeting

o Regular feedback

- Standardised procedures

o Documentation

\footnotetext{
${ }^{1}$ The coding tree was simplified for the purpose of this article.
} 
Relational dimension of social capital

- Trust

- Team identity

- Customer-supplier relationship

- Role expectations, role clarity

- Mentoring relationship

- Subgroup formation

- Competition between national subgroups

- Shared goals

- Conflicts

- Scapegoating

- Interpersonal affect

- Satisfaction

Cognitive dimension of social capital

- Shared understanding

- Skill levels of Indian employees

- Work experience of Indian employees

- Cultural differences between team members

Efficacy

- Knowledge creation and innovation

- Intercultural difficulties

- Language difficulties

Outcome expectations

- Performance, quality

- Efficiency

- Workload

- Coordination effort

- Amount of queries

- Alternative tasks for German employees

- Professional learning, career effects

- Loss of skills on German side

- Intercultural learning experience

- Job security

- Organisational benefit

Organisational context

- Captive versus non-captive

- Management strategy on higher level

- Clarity of management strategy on higher level

- Localisation-centralisation strategies

- Restructuring phase, undeveloped processes

- Info exchange between Indian colleagues

- Technical facilities in Indian subsidiary

- Training, intercultural training, team workshops

Individuals' characteristics

Task characteristics 
- Coding versus function development

- End customer interface

- Repeated vs. one-off tasks

- Simple vs. complex tasks

- Specialist vs. allrounders tasks

- Task fragmentation

- Task interdependence

- Workload fluctuation

Time factors

- Development over time

- Length of collaboration so far

- Speed of transfer 
APPENDIX C. Data analysis: Key themes and illustrative quotes ${ }^{2}$

Structural dimension of social capital

\begin{tabular}{|l|l|}
\hline \multicolumn{1}{|c|}{ Key themes } & \multicolumn{1}{c|}{ Illustrative quotes } \\
\hline $\begin{array}{l}\text { Distance/visits and } \\
\text { knowledge transfer } \\
\text { ability }\end{array}$ & $\begin{array}{l}\text { 'It is simply hard to build up knowledge over the distance. } \\
\text { The strategy is simply to try and use the people [Indian } \\
\text { colleagues] who are over here as multiplicators when they } \\
\text { are back in India.' (Respondent 2, Group leader) }\end{array}$ \\
\hline $\begin{array}{l}\text { Visits and shared } \\
\text { understanding }\end{array}$ & $\begin{array}{l}\text { 'A lot of the communication simply takes place across desks, } \\
\text { or the other person is on the phone and you hear some of it, } \\
\text { this helps a lot. You only have a meeting once or twice a } \\
\text { week and have to try and provide information in a } \\
\text { compressed form, and if you forget to provide something, } \\
\text { then it ... does not arrive in India.' (Respondent 8, Team } \\
\text { leader) }\end{array}$ \\
\hline Visits and trust & $\begin{array}{l}\text { 'When you have collaborated with someone over here for a } \\
\text { month or three months or so and have talked through one or } \\
\text { the other work package with him, when you know how he } \\
\text { works, how structured his work is, and so on, then you } \\
\text { somehow tend to give tasks to exactly this person after he } \\
\text { has returned to India, because you have achieved a certain } \\
\text { trust relationship.' (Respondent 3, Team leader) }\end{array}$ \\
\hline $\begin{array}{l}\text { Visits and team } \\
\text { identity }\end{array}$ & $\begin{array}{l}\text { 'The integration into the team is of course difficult over the } \\
\text { big distance. What we keep noticing is that once the [Indian] } \\
\text { colleagues have been over here, we have a different } \\
\text { connection with them. Colleagues who have been here are } \\
\text { integrated into the team, the German-Indian team, in a } \\
\text { different way than if you know a colleague only from a } \\
\text { picture on the intranet.' (Respondent 3, Team leader) }\end{array}$ \\
\hline $\begin{array}{l}\text { Network stability and } \\
\text { knowledge transfer } \\
\text { ability }\end{array}$ & $\begin{array}{l}\text { With these short cycles [of tenure] that you have in India, it } \\
\text { will be very hard to build system knowledge over there, I } \\
\text { believe.' (Respondent 10, Group leader) }\end{array}$ \\
\hline
\end{tabular}

Relational dimension of social capital

\begin{tabular}{|l|l|}
\hline Key themes & Illustrative quotes \\
\hline $\begin{array}{l}\text { Trust and asking } \\
\text { questions/knowledge } \\
\text { transfer ability }\end{array}$ & $\begin{array}{l}\text { 'Simply this ability to admit not knowling something ... I } \\
\text { have the impression that this is much harder for Indian } \\
\text { colleagues. Simply to say: 'I don't know, but if you know, }\end{array}$ \\
\hline
\end{tabular}

\footnotetext{
${ }^{2}$ For purposes of brevity, in this appendix we exhibit a much shorter version of the actual tables used during data analysis.
} 


\begin{tabular}{|l|l|}
\hline & $\begin{array}{l}\text { please tell me.' That's where you just have to create a } \\
\text { trust basis.' (Respondent 15, Project member) }\end{array}$ \\
\hline $\begin{array}{l}\text { Shared team identity } \\
\text { versus customer- } \\
\text { supplier relationship; } \\
\text { and open } \\
\text { communication }\end{array}$ & $\begin{array}{l}\text { 'Well, in a German team, I would also expect that there is } \\
\text { a customer-supplier relationship ... but then that the } \\
\text { supplier sometimes also asks the customer in detail why } \\
\text { he wants to have something, and simply that you } \\
\text { communicate openly. And such open communication is } \\
\text { difficult with India, if you don't really know each other in } \\
\text { person. And if there is then also the opinion 'We are the } \\
\text { Germans' suppliers and we have to behave in an } \\
\text { obedient or whatever way and not ask to much.' This is of } \\
\text { course not beneficial.' (Respondent 4, Project leader) }\end{array}$ \\
\hline
\end{tabular}

\section{Cognitive dimension of social capital}

\begin{tabular}{|l|l|}
\hline Key themes & Illustrative quotes \\
\hline $\begin{array}{l}\text { Differences in } \\
\text { contextual } \\
\text { understanding } \\
\text { regarding customer } \\
\text { requirements, head } \\
\text { office strategies, and } \\
\text { software system; and } \\
\text { knowledge transfer } \\
\text { ability }\end{array}$ & $\begin{array}{l}\text { 'Knowledge transfer is not that great, I would say. ... Because } \\
\text { we act as a knowledge filter for Indian colleageus, through } \\
\text { our contact to the customer and the platform and the big } \\
\text { world of [the larger department] ... at our location. They are } \\
\text { system kowledge is always relatively scarce.' (Respondent } \\
\text { 18, Project member) }\end{array}$ \\
\hline $\begin{array}{l}\text { Differences in } \\
\text { contextual } \\
\text { understanding } \\
\text { regarding application } \\
\text { domain; and } \\
\text { knowledge transfer } \\
\text { ability }\end{array}$ & $\begin{array}{l}\text { 'On the Indian side, there are the developers, the software } \\
\text { developers for the tool, the tool- and databank experts. On } \\
\text { the German side, there is then an application expert, who } \\
\text { may be a mechanical engineer or something similar. Without } \\
\text { wanting to offend anyone: They speak a different language. } \\
\text { The application expert sees it through his lens, the developer } \\
\text { on the Indian side sees it through his lens. And these two } \\
\text { perspectives are sometimes relatively different, which makes } \\
\text { communication a bit difficult there.' (Respondent 21, Team } \\
\text { leader) }\end{array}$ \\
\hline
\end{tabular}

\section{Efficacy}

\begin{tabular}{|l|l|}
\hline Key themes & Illustrative quotes \\
\hline $\begin{array}{l}\text { Knowledge transfer } \\
\text { efficacy; and } \\
\text { knowledge transfer } \\
\text { willingness }\end{array}$ & $\begin{array}{l}\text { '... the [German] colleague said: 'If I get another three to } \\
\text { four new [Indian] colleagues now, again and again, then I } \\
\text { won't participate any more.' (Respondent 4, Project leader) }\end{array}$ \\
\hline $\begin{array}{l}\text { Intercultural } \\
\text { communication } \\
\text { efficacy; and }\end{array}$ & $\begin{array}{l}\text { 'If I want to work with someone and enjoy being on the } \\
\text { phone with him, then I will do it, with my own drive. Whereas } \\
\text { when I have to do it, at a certain appointment, and the }\end{array}$ \\
\hline
\end{tabular}



not make an effort to make a new appointment. ... Working to rules, so to say.' (Respondent 4, Project leader)

\section{Outcome expectations}

\begin{tabular}{|l|l|}
\hline Key themes & Illustrative quotes \\
\hline $\begin{array}{l}\text { Expectation of } \\
\text { performance } \\
\text { outcomes; and } \\
\text { knowledge transfer } \\
\text { willingness }\end{array}$ & $\begin{array}{l}\text { 'If you do not hand over sufficient information [to Indian } \\
\text { colleagues], you have troubles later on. Everyone knows } \\
\text { that. Withholding information - I do not believe it happens.' } \\
\text { (Respondent 1, Global coordination) }\end{array}$ \\
\hline $\begin{array}{l}\text { Expectation of } \\
\text { workload outcomes; } \\
\text { and knowledge } \\
\text { transfer willingness }\end{array}$ & $\begin{array}{l}\text { 'The frustration can be seen in people saying: 'They [the } \\
\text { Indian colleagues] shall do things on their own, now.' ... } \\
\text { because they keep coming with additional questions, this } \\
\text { leads to a bit of a boycott from time to time.' (Respondent 19, } \\
\text { Team leader) }\end{array}$ \\
\hline $\begin{array}{l}\text { Expectation of } \\
\text { outcomes for task } \\
\text { characteristics; and } \\
\text { knowledge transfer } \\
\text { willingness }\end{array}$ & $\begin{array}{l}\text { 'The tasks of the German system test team are changing, } \\
\text { therefore it comes easier [to German colleagues] to transfer } \\
\text { tasks. Without the Indian colleagues, we would not be able to } \\
\text { cope with our tasks over here any more.' (Respondent 25, } \\
\text { Team leader) }\end{array}$ \\
\hline $\begin{array}{l}\text { Expectation of } \\
\text { outcomes for job } \\
\text { security }\end{array}$ & $\begin{array}{l}\text { '... am aware that once ... people's substance is threatened, } \\
\text { this will influence the decision to support this transfer [of } \\
\text { knowledge]... there must be someone who receives the } \\
\text { knowhow, but there also has to be someone who hands it } \\
\text { over, and a forced hand-over of knowhow does not work, I } \\
\text { believe.' (Respondent 13, Project member) }\end{array}$ \\
\hline
\end{tabular}

